\title{
Dynamic Cournot Duopoly with Intertemporal Capacity Constraints
}

Citation for published version (APA):

van den Berg, A. H. J., Bos, I., Herings, P. J. J., \& Peters, H. J. M. (2012). Dynamic Cournot Duopoly with Intertemporal Capacity Constraints. International Journal of Industrial Organization, 30(2), 174-192. https://doi.org/10.1016/j.ijindorg.2011.08.002

Document status and date:

Published: 01/03/2012

DOI:

10.1016/j.ijindorg.2011.08.002

Document Version:

Publisher's PDF, also known as Version of record

Document license:

Taverne

Please check the document version of this publication:

- A submitted manuscript is the version of the article upon submission and before peer-review. There can be important differences between the submitted version and the official published version of record.

People interested in the research are advised to contact the author for the final version of the publication, or visit the DOI to the publisher's website.

- The final author version and the galley proof are versions of the publication after peer review.

- The final published version features the final layout of the paper including the volume, issue and page numbers.

Link to publication

\footnotetext{
General rights rights.

- You may freely distribute the URL identifying the publication in the public portal. please follow below link for the End User Agreement:

www.umlib.nl/taverne-license

Take down policy

If you believe that this document breaches copyright please contact us at:

repository@maastrichtuniversity.nl

providing details and we will investigate your claim.
}

Copyright and moral rights for the publications made accessible in the public portal are retained by the authors and/or other copyright owners and it is a condition of accessing publications that users recognise and abide by the legal requirements associated with these

- Users may download and print one copy of any publication from the public portal for the purpose of private study or research.

- You may not further distribute the material or use it for any profit-making activity or commercial gain

If the publication is distributed under the terms of Article $25 \mathrm{fa}$ of the Dutch Copyright Act, indicated by the "Taverne" license above, 


\title{
Dynamic Cournot duopoly with intertemporal capacity constraints ${ }^{\text {is }}$
}

\author{
Anita van den Berg ${ }^{a}$, Iwan Bos ${ }^{b}$, P. Jean-Jacques Herings ${ }^{c, *}$, Hans Peters ${ }^{a}$ \\ a Department of Quantitative Economics, Maastricht University, The Netherlands \\ ${ }^{\mathrm{b}}$ Department of Organization \& Strategy, Maastricht University, The Netherlands \\ c Department of Economics, Maastricht University, The Netherlands
}

\section{A R T I C L E I N F O}

\section{Article history:}

Received 22 March 2010

Received in revised form 8 July 2011

Accepted 22 August 2011

Available online 26 August 2011

\section{JEL classification:}

D43

L13

Keywords:

Dynamic duopoly

Cournot competition

Intertemporal capacity constraints

Commitment

\begin{abstract}
A B S T R A C T
This paper studies a dynamic Cournot duopoly in which suppliers have a limited amount of products available for two consecutive periods. We derive optimal sales strategies and analyze welfare effects with and without commitment. Under commitment, strategies do not depend on the rival's realized sales. In this case, there is a unique Nash equilibrium for any allocation of initial supplies and prices increase over time. Absent commitment, sellers can adjust their supply decision after the first period. In this case, a subgame perfect Nash equilibrium does not always exist and prices may decline over time. A more asymmetric allocation of stocks generally leads to higher first-period prices, whereas the impact on second-period prices is ambiguous. The larger firm typically prefers not to commit, whereas the smaller firm is better off under commitment. Commitment generates a higher total surplus and (almost always) a higher consumer surplus. Our findings thus suggest that market transparency or flexible supply contracts can adversely affect welfare in situations where production precedes sales and firms face an intertemporal capacity constraint.
\end{abstract}

(c) 2011 Elsevier B.V. All rights reserved.

\section{Introduction}

In his pioneering work Recherches sur les Principes Mathematiques de la Theorie des Richesses published in 1838, Augustin Cournot explained his by now famous duopoly theory. In the original version, Cournot considers the case of two profit-maximizing spring water suppliers who sell bottles of identical quality at zero costs. ${ }^{1}$ Both sellers simultaneously and independently decide how many bottles to bring to the market on the basis of the belief that the output of their rival remains constant and the market clears. The optimal supply decisions in this case are well understood and would be no different if firms were to compete repeatedly provided that both have an abundance of resources available. Suppose, however, that spring water supplies are limited. Specifically, suppose that suppliers interact for a number of periods and that there is not enough water available to supply the unconstrained Cournot equilibrium output in each period. The recognition that firms may find themselves confronted with such an intertemporal capacity constraint generates a number of interesting questions. What are the optimal sales strategies in this case? How do output decisions depend on the level and allocation of initial supplies?

\footnotetext{
We appreciate the comments and suggestions of participants at the 2008 European Association for Research in Industrial Economics conference, the editor and an anonymous referee. Jean-Jacques Herings gratefully acknowledges financial support of the Netherlands Organization for Scientific Research (NWO).

* Corresponding author at: P.O. Box 616, 6200 MD Maastricht, The Netherlands.

E-mail address: p.herings@maastrichtuniversity.nl (P.J.J. Herings).

1 See Bacon's translation of Cournot (1838), Chapter 7.
}

What are the implications of optimal supply decisions for welfare? In this paper, we address these and related questions.

The key characteristic of an intertemporal capacity constraint is that current supply decisions affect future profit opportunities; selling more of the stock today leaves less to sell tomorrow and vice versa. This dynamic trade-off can be found in a wide variety of economic situations. Akin to the spring water example, it quite naturally applies to exhaustible resource markets. For example, oil companies typically control a limited number of oil fields and current sales put a restraint on what can be sold in the future. Similarly, in many markets production is often temporarily given. For instance, a ticket seller who has tickets for a concert or football match has a choice between selling these, say, 3 months in advance or around the stadium on the day of the event instead. Other examples include fishery (under quota constraints), flight seats, hotel rooms, limited edition goods, fashionable items, specialized agricultural products, emissions trading, etcetera. What all these cases have in common is that a seller who attempts to maximize his profits should not only take account of its rival's quantity of output, but additionally needs to consider how its current supply decision affects future sales opportunities.

The purpose of this research is to gain understanding of strategic firm behavior and welfare implications in situations where firms are capacity-constrained over time. Toward that end, we study a dynamic Cournot duopoly in which suppliers have a limited amount of products available for two consecutive periods. We distinguish two settings. In the first setting, suppliers commit to their sales strategies, which means that supply decisions are independent of the rival's 
realized sales. For example, sellers may lack information about sales of competitors so that after the first period it is unclear how much of the rival's stock has been sold. Also, sellers and buyers may sign supply contracts specifying desired volumes for each period. In the second setting, suppliers can adjust their sales strategy after the first period. This situation corresponds to more transparent markets and flexible supply contracts.

Summarizing some of our main findings, there is a unique purestrategy Nash equilibrium for any allocation of initial supplies under commitment, whereas under non-commitment a subgame perfect Nash equilibrium in pure strategies may not exist. With commitment, prices weakly increase over time and an increase in stocks ceteris paribus leads to higher profits. By contrast, prices may decline and increasing stocks may lead to lower profits absent commitment. A more asymmetric allocation of stocks generally leads to higher first-period prices, whereas the impact on second-period prices is ambiguous. Larger firms typically prefer not to commit, whereas commitment is beneficial for smaller firms, society at large and (almost always) for buyers. Consequently, our findings suggest that an increase in market transparency or flexibility of supply contracts can have a negative effect on welfare.

To our knowledge, our study is among the first to address the impact of intertemporal capacity constraints on optimal sales strategies and welfare. In fact, the only other paper we are aware of that considers capacity constraints over time is Biglaiser and Vettas (2004). This paper studies a setting in which two equally sized firms compete in price for two periods, while facing one or multiple strategic buyers with unit demand for a durable homogeneous good. Sellers do not commit to their price choices. Among other things, Biglaiser and Vettas (2004) establish that in this case there exists no pure-strategy Nash equilibrium. Moreover, it is shown that buyers are hurt by their ability to behave strategically and consequently have an incentive to commit to myopic behavior. Our setting is quite different as we consider quantity competition under both commitment and noncommitment and explore variations in the level and allocation of initial stocks. Moreover, in our case, buyers do not behave strategically. An interesting complementary finding is that consumers are (almost always) better off under commitment. Thus, our analysis reveals that buyers may also have a preference for commitment on the supply side.

There is a rich source of literature on strategic firm behavior under capacity constraints, where capacities are either endogenous or exogenously given and firms compete in price or quantity. Contributions include, among others, Levitan and Shubik (1972), Kreps and Scheinkman (1983), Osborne and Pitchik (1986), Bikhchandani and Mamer (1993), Gabszewicz and Poddar (1997), Besanko and Doraszelski (2004) and Laye and Laye (2008). Additionally, Saloner (1987) modifies the Cournot duopoly by considering two production stages before the market clears and shows that in this case there is a unique subgame perfect Nash equilibrium. This setting has been extended by Pal (1991, 1996) who allows for cost differences and mixed-strategy equilibria and Kovenock and Roy (1998) who relax the assumption of market clearing. In none of these papers, however, firms face an intertemporal capacity constraint. Thus, the key difference between our work and the available literature on strategic firm behavior under capacity constraints is that we consider a setting in which current sales opportunities depend on past supply decisions.

As the spring water example above illustrates, our study is also related to the literature on exhaustible or nonrenewable resources. Theories in this field date back as far as Hotelling (1931) and have been advanced by, among others, Lewis and Schmalensee (1980), Reinganum and Stokey (1985), Loury (1986), Gaudet and Van Long (1994) and, more recently, Salo and Tahvonen (2001). The majority of literature in this area assumes commitment and, as far as results are comparable, our findings are similar. As to non-commitment, Reinganum and Stokey (1985) consider oligopoly extraction of a common property resource and show that the length of the commitment period can have a major impact on equilibrium firm behavior. Salo and Tahvonen (2001) show that markets for exhaustible resources can become more competitive over time absent commitment as rising prices may attract additional suppliers.

This paper proceeds as follows. The next section introduces the Cournot duopoly model with intertemporal capacity constraints. Section 3 examines strategic firm behavior under commitment and non-commitment. Section 4 uses the optimal sales strategies to explore the welfare implications for consumers and society at large. Section 5 concludes. All proofs are provided in Appendix A. For ease of reading, most of the computational details are relegated to Appendices B and C.

\section{Model}

Consider an industry in which two profit-maximizing firms, $i=1$, 2 , have a fixed and finite amount of a homogeneous good denoted by $S_{i} \geq 0$. As these products have been produced (or bought) in advance, production costs are sunk. Given their stocks, both sellers compete in quantity for two consecutive periods. The quantities sold by firm $i$ in period 1 and period 2 are respectively denoted by $q_{i}$ and $r_{i}$, with $q_{i}+$ $r_{i} \leq S_{i}$. Firms may have residual supply at the end of the second period. To keep the analysis tractable, we assume linear market demand. Specifically, inverse demand in each period is given by

$P(Q)=1-Q$

where $Q=q_{1}+q_{2}$ in the first and $Q=r_{1}+r_{2}$ in the second period. Second-period profits are discounted at a common discount factor $\delta \in(0,1]$.

In the following, we consider two settings. In the first setting, firms commit to a sales strategy. That is, both unconditionally determine how many products to offer in each period. In particular, this implies that the supply decision of a firm in period 2 is not affected by the first-period sales of its rival. This may be due to a lack of (or lag in) relevant information about sales and profits. For example, profits made in previous periods may not yet be available when deciding on current quantities of output. Alternatively, volumes of output may have been specified in advance by means of a supply contract. Formally, firm $i$ 's strategy space under commitment is given by $\Gamma_{i}=\left\{\left(q_{i}, r_{i}\right) \in \mathbb{R}_{+}^{2} \mid q_{i}+r_{i} \leq S_{i}\right\}$. In the second setting, sellers do not commit to their sales strategy. In this case, a firm's optimal supply decision in the second period is potentially affected by the realized sales of its rival in the first period. Thus, second-period strategies are conditional on first-period sales. We define $F_{i}=\left\{f_{i}:\left[0, S_{1}\right] \times[0\right.$, $\left.\left.S_{2}\right] \rightarrow\left[0, S_{i}\right] \mid q_{i}+f_{i}\left(q_{1}, q_{2}\right) \leq S_{i}\right\}$ as the set of functions that assign a feasible second-period quantity of output to every possible combination of first-period sales. Firm $i$ 's strategy space is then $\Sigma_{i}=\left[0, S_{i}\right] \times F_{i}$.

\section{Strategic firm behavior}

\subsection{Commitment}

Under commitment, a firm determines its sales strategy independent of its rival's realized sales. Given strategies $\left(q_{1}, r_{1}\right) \in \Gamma_{1}$ and $\left(q_{2}\right.$, $\left.r_{2}\right) \in \Gamma_{2}$, firm $i$ 's profit is given by

$\Pi_{i}\left(q_{1}, r_{1}, q_{2}, r_{2}\right)=q_{i} P\left(q_{i}+q_{j}\right)+\delta r_{i} P\left(r_{i}+r_{j}\right)$.

In choosing its sales path $\left(q_{i}, r_{i}\right)$, firm $i$ takes the sales path $\left(q_{j}, r_{j}\right)$ of firm $j$ as given (where the subscripts $i$ and $j$ are used to indicate the two competitors). Firm $i$ therefore solves the following constrained maximization problem:

$\max _{q_{1} r_{i}} \Pi_{i}\left(q_{1}, r_{1}, q_{2}, r_{2}\right)$ 
subject to

$q_{i}, r_{i} \geq 0$ and $q_{i}+r_{i} \leq S_{i}$

The result is a continuous best response function $\gamma_{i} \in \Gamma_{i}$ :

$$
\gamma_{i}\left(q_{j}, r_{j}\right)=\left\{\begin{array}{cl}
\left(S_{i}, 0\right) & \left\{\begin{array}{l}
\text { if }\left[q_{j}-\delta r_{j}<1-\delta-2 S_{i},\right. \\
\left.q_{j}+r_{j} \leq 2-2 S_{i} \text { and } q_{j}, r_{j} \leq 1\right] \\
\text { or }\left[q_{j} \leq 1-2 S_{i} \text { and } r_{j}>1\right]
\end{array}\right. \\
\left(0, S_{i}\right) & \left\{\begin{array}{l}
\text { if }\left[q_{j}-\delta r_{j}>1-\delta+2 \delta S_{i},\right. \\
\left.q_{j}+r_{j} \leq 2-2 S_{i} \text { and } q_{j}, r_{j} \leq 1\right] \\
\text { or }\left[q_{j}>1 \text { and } r_{j} \leq 1-2 S_{i}\right.
\end{array}\right] \\
\left(\frac{1-\delta+2 \delta S_{i}-q_{j}+\delta r_{j}}{2+2 \delta}, \frac{2 S_{i}-1+\delta+q_{j}-\delta r_{j}}{2+2 \delta}\right) & \left\{\begin{array}{c}
\text { if } 1-\delta-2 S_{i} \leq q_{j}-\delta r_{j} \leq \\
1-\delta+2 \delta S_{i}, \\
q_{j}+r_{j} \leq 2-2 S_{i} \text { and } q_{j}, r_{j} \leq 1
\end{array}\right. \\
\left(\frac{1}{2}-\frac{1}{2} q_{j}, \frac{1}{2}-\frac{1}{2} r_{j}\right) & \left\{\begin{array}{c}
\text { if } q_{j}+r_{j}>2-2 S_{i} \\
\text { and } q_{j}, r_{j} \leq 1
\end{array}\right. \\
\left(\frac{1}{2}-\frac{1}{2} q_{j}, 0\right) & \left\{\begin{array}{c}
\text { if } 1-2 S_{i}<q_{j} \leq 1 \\
\text { and } r_{j}>1
\end{array}\right. \\
\left(0, \frac{1}{2}-\frac{1}{2} r_{j}\right) & \left\{\begin{array}{c}
\text { if } 1-2 S_{j}<r_{j} \leq 1 \\
\text { and } q_{j}>1
\end{array}\right. \\
(0,0) & \text { if } q_{j}, r_{j}>1 .
\end{array}\right.
$$

These seven cases are mutually exclusive and the best response against $\left(q_{j}, r_{j}\right)$ is unique. A pair of strategies $\left(q_{1}^{*}, r_{1}^{*}, q_{2}^{*}, r_{2}^{*}\right)$ constitutes a Nash equilibrium if and only if

$\Pi_{1}\left(q_{1}^{*}, r_{1}^{*}, q_{2}^{*}, r_{2}^{*}\right) \geq \Pi_{1}\left(q_{1}, r_{1}, q_{2}^{*}, r_{2}^{*}\right)$ for all $\left(q_{1}, r_{1}\right) \in \Gamma_{1}$,

$\Pi_{2}\left(q_{1}^{*}, r_{1}^{*}, q_{2}^{*}, r_{2}^{*}\right) \geq \Pi_{2}\left(q_{1}^{*}, r_{1}^{*}, q_{2}, r_{2}\right)$ for all $\left(q_{2}, r_{2}\right) \in \Gamma_{2}$,

\begin{tabular}{|c|c|c|c|}
\hline & Parameter conditions & Period 1 & Period 2 \\
\hline$\left(\mathrm{X}_{\mathrm{ll}}^{c}\right)$ & $\begin{array}{l}0 \leq S_{1}<\frac{1}{2}-\frac{1}{2} S_{2}-\frac{1}{2} \delta \\
0 \leq S_{2}<\frac{1}{2}-\frac{1}{2} S_{1}-\frac{1}{2} \delta\end{array}$ & $\begin{array}{l}q_{1}^{c}=S_{1} \\
q_{2}^{c}=S_{2}\end{array}$ & $\begin{array}{l}r_{1}^{c}=0 \\
r_{2}^{c}=0\end{array}$ \\
\hline$\left(X_{\operatorname{lm}}^{c}\right)$ & $\begin{array}{l}0 \leq S_{1}<\frac{1}{3}-\frac{1}{3} \delta \\
\frac{1}{2}-\frac{1}{2} \delta-\frac{1}{2} S_{1} \leq S_{2} \leq 1-\frac{1}{2} S_{1}\end{array}$ & $\begin{array}{l}q_{1}^{c}=S_{1} \\
q_{2}^{c}=\frac{1-S_{1}-\delta+2 \delta S_{2}}{2+2 \delta}\end{array}$ & $\begin{array}{l}r_{1}^{c}=0 \\
r_{2}^{c}=\frac{2 S_{2}+S_{1}-1+\delta}{2+2 \delta}\end{array}$ \\
\hline$\left(\mathrm{X}_{\mathrm{ml}}^{\mathrm{c}}\right)$ & $\begin{array}{l}\frac{1}{2}-\frac{1}{2} \delta-\frac{1}{2} S_{2} \leq S_{1} \leq 1-\frac{1}{2} S_{2} \\
0 \leq S_{2}<\frac{1}{3}-\frac{1}{3} \delta\end{array}$ & $\begin{array}{l}q_{1}^{c}=\frac{1-\delta+2 \delta S_{1}-S_{2}}{2+2 \delta} \\
q_{2}^{c}=S_{2}\end{array}$ & $\begin{aligned} r_{1}^{c} & =\frac{2 S_{1}+S_{2}-1+\delta}{2+2 \delta} \\
r_{2}^{c} & =0\end{aligned}$ \\
\hline$\left(\mathrm{X}_{\mathrm{lh}}^{\mathrm{c}}\right)$ & $\begin{array}{l}0 \leq S_{1}<\frac{1}{3}-\frac{1}{3} \delta \\
1-\frac{1}{2} S_{1}<S_{2}\end{array}$ & $\begin{array}{l}q_{1}^{c}=S_{1} \\
q_{2}^{c}=\frac{1}{2}-\frac{1}{2} S_{1}\end{array}$ & $\begin{array}{l}r_{1}^{c}=0 \\
r_{2}^{c}=\frac{1}{2}\end{array}$ \\
\hline$\left(\mathrm{X}_{\mathrm{hl}}^{c}\right)$ & $\begin{array}{l}1-\frac{1}{2} S_{2}<S_{1} \\
0 \leq S_{2}<\frac{1}{3}-\frac{1}{3} \delta\end{array}$ & $\begin{aligned} q_{1}^{c} & =\frac{1}{2}-\frac{1}{2} S_{2} \\
q_{2}^{c} & =S_{2}\end{aligned}$ & $\begin{array}{l}r_{1}^{c}=\frac{1}{2} \\
r_{2}^{c}=0\end{array}$ \\
\hline$\left(\mathrm{X}_{\mathrm{mm}}^{c}\right)$ & $\begin{array}{l}\frac{1}{3}-\frac{1}{3} \delta \leq S_{1} \leq 1-\frac{1}{2} S_{2} \\
\frac{1}{3}-\frac{1}{3} \delta \leq S_{2} \leq 1-\frac{1}{2} S_{1}\end{array}$ & $\begin{array}{l}q_{1}^{c}=\frac{1-\delta+3 \delta S_{1}}{3+3 \delta} \\
q_{2}^{c}=\frac{1-\delta+3 \delta S_{2}}{3+3 \delta}\end{array}$ & $\begin{array}{l}r_{1}^{c}=\frac{3 S_{1}-1+\delta}{3+3 \delta} \\
r_{2}^{c}=\frac{3 S_{2}-1+\delta}{3+3 \delta}\end{array}$ \\
\hline$\left(\mathrm{X}_{\mathrm{mh}}^{c}\right)$ & $\begin{array}{l}\frac{1}{3}-\frac{1}{3} \delta \leq S_{1} \leq \frac{2}{3} \\
1-\frac{1}{2} S_{1}<S_{2}\end{array}$ & $\begin{array}{l}q_{1}^{c}=\frac{1-\delta+3 \delta S_{1}}{3+3 \delta} \\
q_{2}^{c}=\frac{2+4 \delta-3 \delta S_{1}}{6+6 \delta}\end{array}$ & $\begin{array}{l}r_{1}^{c}=\frac{3 S_{1}-1+\delta}{3+3 \delta} \\
r_{2}^{c}=\frac{4+2 \delta-3 S_{1}}{6+6 \delta}\end{array}$ \\
\hline$\left(\mathrm{X}_{\mathrm{hm}}^{c}\right)$ & $\begin{array}{l}1-\frac{1}{2} S_{2}<S_{1} \\
\frac{1}{3}-\frac{1}{3} \delta<S_{2} \leq \frac{2}{3}\end{array}$ & $\begin{array}{l}q_{1}^{c}=\frac{2+4 \delta-3 \delta S_{2}}{6+6 \delta} \\
q_{2}^{c}=\frac{1-\delta+3 \delta S_{2}}{3+3 \delta}\end{array}$ & $\begin{array}{l}r_{1}^{c}=\frac{4+2 \delta-3 S_{2}}{6+6 \delta} \\
r_{2}^{c}=\frac{3 S_{2}-1+\delta}{3+3 \delta}\end{array}$ \\
\hline$\left(\mathrm{X}_{\mathrm{hh}}^{c}\right)$ & $\begin{array}{l}\frac{2}{3}<S_{1} \\
\frac{2}{3}<S_{2}\end{array}$ & $\begin{array}{l}q_{1}^{c}=\frac{1}{3} \\
q_{2}^{c}=\frac{1}{3}\end{array}$ & $\begin{aligned} r_{1}^{c} & =\frac{1}{3} \\
r_{2}^{c} & =\frac{1}{3}\end{aligned}$ \\
\hline
\end{tabular}

or, equivalently, $\gamma_{1}\left(q_{2}^{*}, r_{2}^{*}\right)=\left(q_{1}^{*}, r_{1}^{*}\right)$ and $\gamma_{2}\left(q_{1}^{*}, r_{1}^{*}\right)=\left(q_{2}^{*}, r_{2}^{*}\right)$.

For any given initial combination $\left(S_{1}, S_{2}, \delta\right)$, there is a unique Nash equilibrium. These equilibria are specified in Table 1 and illustrated in

Table 1

Equilibria with commitment.

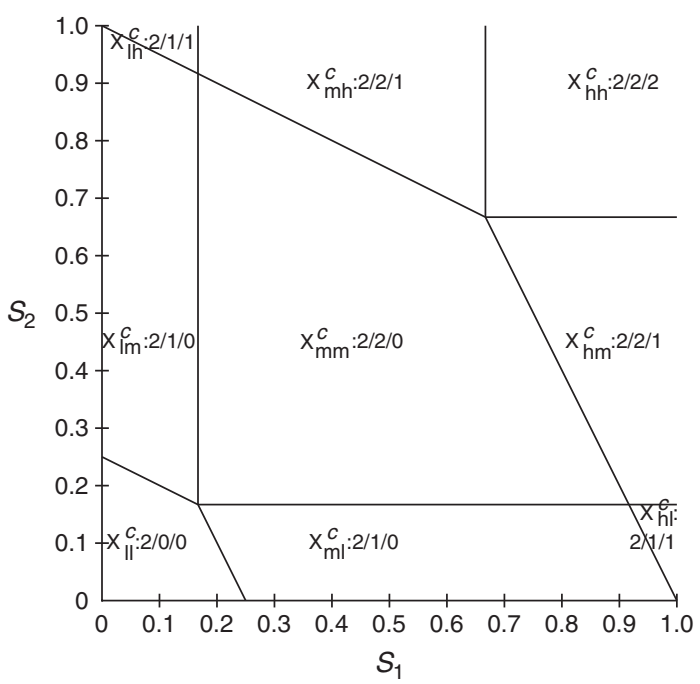

Fig. 1. Equilibrium outcome regions under commitment and the number of active firms in each period for $\delta=0.5$.

Fig. 1. The figure shows combinations of $S_{1}, S_{2}$ at a given $\delta .{ }^{2}$ The superscript ' $c$ ' stands for commitment and the subscript indicates available supply of respectively firm $i$ and firm $j$, where 'l' stands for low, ' $m$ ' for medium and ' $h$ ' for high. Additionally, Fig. 1 depicts the number of firms active in each period. Specifically, $N_{1} / N_{2} / N_{r}$ indicates respectively the number of firms with strictly positive sales in the first period, the number of firms with strictly positive sales in the second period and the number of firms with residual supply at the end of the second period.

Fig. 1 reveals that the number of firms active in each period is positively correlated with the amount of available products, all else equal. If firm 1 has limited supplies (as in regions $\mathrm{X}_{\mathrm{ll}}^{\mathrm{c}}, \mathrm{X}_{\mathrm{lm}}^{\mathrm{c}}$, and $\mathrm{X}_{\mathrm{lh}}^{\mathrm{c}}$ ), then it will sell all its products in the first period. It is important to highlight that these regions are non-empty only for discount factors strictly below one. Discounting of second-period profits provides firms with an incentive to sell as soon as possible. For sufficiently low stocks, marginal revenue in the first period exceeds marginal revenue in the second period as long as $\delta$ is not too high. Therefore, selling everything in the first period is optimal in this case. In the regions $\mathrm{X}_{\mathrm{ml}}^{\mathrm{c}}, \mathrm{X}_{\mathrm{mm}}^{\mathrm{c}}$, and $\mathrm{X}_{\mathrm{mh}}^{\mathrm{c}}$, firm 1 has a moderate number of products available. Here, profit-maximization requires a division of sales such that marginal revenue in the first period equals marginal revenue in the second period. In the remaining regions (i.e., $\mathrm{X}_{\mathrm{hl}}^{\mathrm{c}}, \mathrm{X}_{\mathrm{hm}}^{\mathrm{c}}$ and $\mathrm{X}_{\mathrm{hh}}^{\mathrm{c}}$ ), firm 1 has a large stock and faces no capacity constraint. This implies that profits are maximized for each period separately. Moreover, there is residual supply at the end of the second period. A similar reasoning applies to the equilibrium strategy of firm $2 .^{3}$

In light of the above analysis, one question of interest concerns the development of prices. The next proposition shows that prices do not decline under commitment.

Proposition 1. In equilibrium, price weakly increases over time.

Thus, total sales in the second period never exceed total sales in the first period. In fact, a firm will choose its sales path in such a way that marginal revenues for both periods are the same. The only exception is when its capacity is severely limited. In that case, marginal revenue in period 1 always exceeds marginal revenue in period

\footnotetext{
${ }^{2}$ A change in $\delta$ affects the size, but not the shape of the equilibrium regions.

${ }^{3}$ Notice that in region $\mathrm{X}_{\mathrm{hh}}^{\mathrm{c}}$ none of the firms is capacity-constrained. As a result, both optimally choose the unconstrained Cournot equilibrium quantity $\frac{1}{3}$ in each period.
} 
2 and, as a consequence, it is optimal to sell all products in the first period.

Let us finally study the impact of the level and allocation of initial stocks. The next result shows that it is typically beneficial for a firm to have more in stock, all else equal.

Proposition 2. An increase in $S_{i}$ leads to a weak increase in firm i's equilibrium profit.

The following proposition summarizes how the division of initial supplies affects equilibrium outcomes.

Proposition 3. Given aggregate stock $S_{1}+S_{2}$, an increase in $\left|S_{1}-S_{2}\right|$ leads to a weak decrease in first-period aggregate equilibrium sales and a weak increase of first-period equilibrium price. Additionally, it leads to (i) a decrease in second-period aggregate equilibrium sales and an increase of second-period equilibrium price in regions $\mathrm{X}_{\mathrm{mh}}^{\mathrm{c}}$ and $\mathrm{X}_{\mathrm{hm}}^{\mathrm{c}}$ and (ii) an increase in second-period aggregate equilibrium sales and a decrease of second-period equilibrium price in regions $\mathrm{X}_{\mathrm{Im}}^{\mathrm{C}}$ and $\mathrm{X}_{\mathrm{ml}}^{\mathrm{c}}$. It has no effect on second-period aggregate equilibrium sales and second-period equilibrium price in the other regions.

A more asymmetric allocation of stocks leads to higher prices in the first period. In fact, the highest first-period price is obtained in the extreme case in which one firm effectively operates as a monopolist by controlling all initial supplies. Yet, the effect on second-period prices is ambiguous. In particular, observe that prices decline in re-

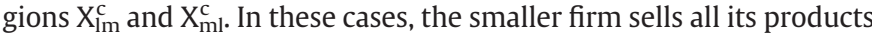
in period 1. A (relative) growth in stock of the larger firm then yields a higher sales level in period 2, which induces a lower second-period market price.

\subsection{Non-commitment}

Let us now consider the case where sales strategies in the second period depend on realized and observed first-period sales. Our objective is to derive and analyze the subgame perfect Nash equilibria of the game absent commitment. Toward that end, we start by evaluating the Nash equilibria in all possible second period subgames. Consider the subgame $q=\left(q_{1}, q_{2}\right)$ in period 2 that results from first-period sales $\left(q_{1}, q_{2}\right)$. Let firm $i$ 's second-period stock be denoted by $T_{i}=S_{i}-$ $q_{i}$ and let $\sigma_{i q}:\left[0, T_{j}\right] \rightarrow\left[0, T_{i}\right]$ be firm $i$ 's best response function in subgame $q$. Thus, for a given sales level $r_{j}$, firm $i$ solves:

$\max _{r_{i}} r_{i} P\left(r_{i}+r_{j}\right)$

subject to

$0 \leq r_{i} \leq T_{i}$

Firm $i$ 's best response in period 2 is then given by

$\sigma_{i q}\left(r_{j}\right)= \begin{cases}T_{i} & \text { if } 0 \leq T_{i} \leq \frac{1}{2}-\frac{1}{2} r_{j}, \\ \max \left\{0, \frac{1}{2}-\frac{1}{2} r_{j}\right\} & \text { otherwise. }\end{cases}$

Quantities $\left(r_{1}^{*}, r_{2}^{*}\right)$ are a Nash equilibrium of the second-period subgame $q$ if and only if $\sigma_{1 q}\left(r_{2}^{*}\right)=r_{1}^{*}$ and $\sigma_{2 q}\left(r_{1}^{*}\right)=r_{2}^{*}$. Each subgame $q$ has a unique Nash equilibrium as specified in Table 2 and illustrated in Fig. $2 .{ }^{4}$ In region $Y_{h h}$, both firms have sufficient residual stock to supply the unconstrained profit-maximizing quantity. In regions $Y_{\mathrm{hl}}$ and $Y_{l h}$, only one supplier is capacity-constrained. In region $Y_{l l}$, both

\footnotetext{
${ }^{4}$ This figure is similar to Fig. 1 in Krishnan and Röller (1993). Their Stage 5 problem coincides with our second-period subgame.
}

Table 2

Second-period equilibrium outcomes.

\begin{tabular}{lllllll}
\hline & $T_{i}$ & $T_{j}$ & $r_{i}$ & $r_{j}$ & Profits $i$ & Profits $j$ \\
\hline$\left(\mathrm{Y}_{\mathrm{hh}}\right)$ & $>\frac{1}{3}$ & $>\frac{1}{3}$ & $\frac{1}{3}$ & $\frac{1}{3}$ & $\overline{9}$ & $\overline{9}$ \\
$\left(\mathrm{Y}_{\mathrm{lh}}\right)$ & $\leq \frac{1}{3}$ & $>\frac{1-T_{i}}{2}$ & $T_{i}$ & $\frac{1-T_{i}}{2}$ & $T_{i}\left(\frac{1-T_{i}}{2}\right)$ & $\left(\frac{1-T_{i}}{2}\right)^{2}$ \\
$\left(\mathrm{Y}_{\mathrm{hl}}\right)$ & $>\frac{1-T_{j}}{2}$ & $\leq \frac{1}{3}$ & $\frac{1-T_{j}}{2}$ & $T_{j}$ & $\frac{\left(1-T_{j}\right)^{2}}{4}$ & $T_{j}\left(\frac{1-T_{j}}{2}\right)$ \\
$\left(\mathrm{Y}_{\mathrm{ll}}\right)$ & $\leq \frac{1-T_{j}}{2}$ & $\leq \frac{1-T_{i}}{2}$ & $T_{i}$ & $T_{j}$ & $T_{i}\left(1-T_{i}-T_{j}\right)$ & $T_{j}\left(1-T_{i}-T_{j}\right)$
\end{tabular}

firms' capacities are binding and they bring their entire stock to the market.

The equilibrium action of firm $i$ in period 2 is given by the function $f_{i}^{*}$ :

$f_{i}^{*}\left(q_{i}, q_{j}\right)= \begin{cases}\frac{1}{3} & \text { if } T_{i}, T_{j}>\frac{1}{3}, \\ \frac{1}{2}-\frac{1}{2} T_{j} & \text { if } T_{i}>\frac{1}{2}-\frac{1}{2} T_{j} \text { and } T_{j} \leq \frac{1}{3} \\ T_{i} & \text { if } T_{i} \leq \frac{1}{3} \text { or } T_{j} \leq 1-2 T_{i} .\end{cases}$

We now replace the second-period subgames with the secondperiod outcomes as induced by $f^{*}$. The result is a one-period reduced game in which the payoffs are given by

$\Pi_{i}^{\mathrm{R}}\left(q_{i}, q_{j}\right)=\Pi_{i}\left(q_{i}, q_{j}, f_{i}^{*}\left(q_{i}, q_{j}\right), f_{j}^{*}\left(q_{i}, q_{j}\right)\right), \quad 0 \leq q_{i} \leq S_{i}, 0 \leq q_{j} \leq S_{j}$.

The reduced profit function of firm $i$ is then specified as follows.

$$
\begin{aligned}
\Pi_{i}^{\mathrm{R}}\left(q_{i}, q_{j}\right)= & q_{i}\left(1-q_{i}-q_{j}\right)+ \\
& \begin{cases}\frac{1}{9} \delta & \text { if } T_{i}>\frac{1}{3} \text { and } T_{j}>\frac{1}{3} \\
\frac{1}{2} \delta T_{i}\left(1-T_{i}\right) & \text { if } 1-2 T_{j}<T_{i} \leq \frac{1}{3} \\
\frac{1}{4} \delta\left(1-T_{j}\right)^{2} & \text { if } T_{i}>\frac{1}{2}-\frac{1}{2} T_{j} \text { and } T_{j} \leq \frac{1}{3} \\
\delta T_{i}\left(1-T_{i}-T_{j}\right) & \text { if } T_{i} \leq \min \left\{\frac{1}{2}-\frac{1}{2} T_{j}, 1-2 T_{j}\right\}\end{cases}
\end{aligned}
$$

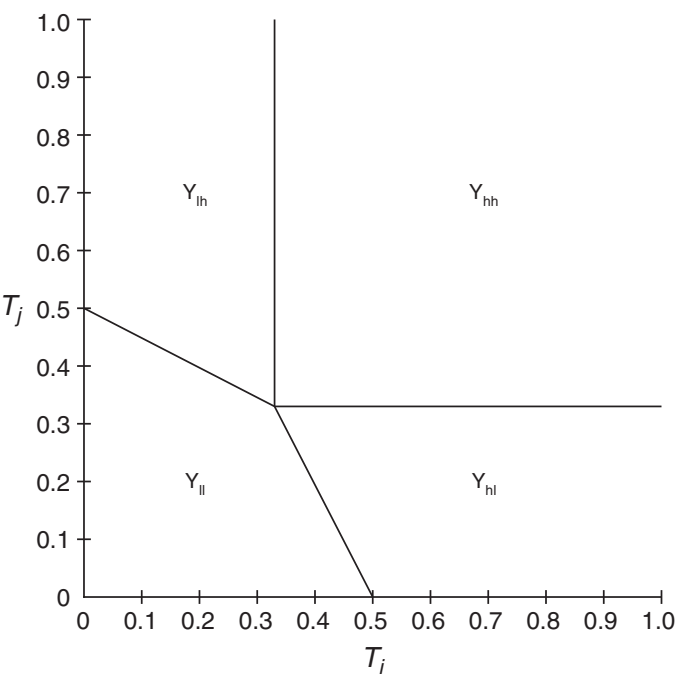

Fig. 2. Second-period equilibrium outcome regions for $\delta=0.5$. 
A pair of strategies $\left(q_{1}^{*}, q_{2}^{*}\right)$ is a Nash equilibrium of the reduced game if and only if it holds that

$\Pi_{1}^{\mathrm{R}}\left(q_{1}^{*}, q_{2}^{*}\right) \geq \Pi_{1}^{\mathrm{R}}\left(q_{1}, q_{2}^{*}\right)$, for all $q_{1} \in\left[0, S_{1}\right]$,

$\Pi_{2}^{\mathrm{R}}\left(q_{1}^{*}, q_{2}^{*}\right) \geq \Pi_{2}^{\mathrm{R}}\left(q_{1}^{*}, q_{2}\right)$, for all $q_{2} \in\left[0, S_{2}\right]$.

A Nash equilibrium $\left(q_{1}^{*}, q_{2}^{*}\right)$ of the reduced game corresponds to a subgame perfect Nash equilibrium $\left(q_{1}^{*}, f_{1}^{*}, q_{2}^{*}, f_{2}^{*}\right)$ of the entire game.

Let us now have a closer look at the reduced best responses and the subgame perfect Nash equilibria. The computational details and derivations can be found in Appendices B and C. To begin, in equilibrium none of the firms will sell in excess of the unconstrained monopoly output.

Lemma 4. For any Nash equilibrium $\left(q_{1}^{*}, q_{2}^{*}\right)$ of the reduced game, it holds that $q_{i}^{*}, q_{j}^{*} \leq \frac{1}{2}$.

In the following, let $\sigma_{i}^{\mathrm{R}}\left(q_{j}\right)$ denote the reduced best response of firm $i$ against $q_{j}$. Quantities $\left(q_{1}^{*}, q_{2}^{*}\right)$ are a Nash equilibrium of the reduced game if and only if $q_{i}^{*} \in \sigma_{i}^{\mathrm{R}}\left(q_{j}^{*}\right)$ and $q_{j}^{*} \in \sigma_{j}^{\mathrm{R}}\left(q_{i}^{*}\right)$. Given $q_{j}$, the reduced profit function is continuous, albeit not always concave. Thus, the reduced best response against $q_{j}$ always exists, but need not be unique. The reduced best response correspondence is upper hemicontinuous, but may not be convex-valued. As a result, a subgame perfect Nash equilibrium in pure strategies may not always exist, which indeed turns out to be the case for some combinations of $S_{i}$, $S_{j}$ and $\delta$.

Combinations of $\left(S_{1}, S_{2}, \delta\right)$ can be partitioned in 12 regions. In each region in which there exists an equilibrium, the equilibria share the same qualitative features and are differentiable functions of $S_{1}, S_{2}$, and $\delta$. The equilibrium regions and outcomes are specified in Table 3 and illustrated in Fig. 3. The superscript 'nc' stands for noncommitment. As before, the subscript indicates available supply of respectively firm $i$ and firm $j$, where 'l' stands for low, ' $m$ ' for medium, ' $\mathrm{m}$ ' for medium-high and ' $h$ ' for high.

As suggested by Fig. 3, the 12 regions are mutually exclusive. This property holds in general.

Theorem 5. There is at most one subgame perfect Nash equilibrium for each combination of $S_{1}, S_{2}$, and $\delta$.

In some cases, an equilibrium does not exist. ${ }^{5}$

Theorem 6. For each $\delta$, there is a set of stock levels $\left(S_{1}, S_{2}\right)$ with nonempty interior for which an equilibrium does not exist.

Akin to the commitment setting, Fig. 3 shows that the number of active firms in each period increases for larger initial supplies. Yet, the price development may be different. By Proposition 1, we know that prices do not decline over time under commitment. If the firstperiod price would exceed the second-period price, then sellers would have an incentive to transfer a part (or all) of their second-period output to period 1. As the next result shows, this may no longer hold absent commitment.

Proposition 7. In regions $\mathrm{X}_{\mathrm{ll}}^{\mathrm{nc}}, \mathrm{X}_{\mathrm{lm}}^{\mathrm{nc}}, \mathrm{X}_{\mathrm{lh}}^{\mathrm{nc}}, \mathrm{X}_{\mathrm{hl}}^{\mathrm{nc}}, \mathrm{X}_{\mathrm{mm}}^{\mathrm{nc}}$ and $\mathrm{X}_{\mathrm{hh}}^{\mathrm{nc}}$, the equilibrium price weakly increases over time. For each $\delta$, there is a set of stock levels $\left(S_{1}, S_{2}\right) \in \mathrm{X}_{\mathrm{mh}}^{\mathrm{nc}} \cup \mathrm{X}_{\mathrm{m}^{\prime} \mathrm{h}}^{\mathrm{nc}} \cup \mathrm{X}_{\mathrm{hm}}^{\mathrm{nc}} \cup \mathrm{X}_{\mathrm{hm}}^{\mathrm{nc}}$, with non-empty interior

\footnotetext{
${ }^{5}$ To be precise, a pure equilibrium may not exist. As the reduced strategy spaces are nonempty compact subsets of $\mathbb{R}$ and the payoff functions $\Pi_{i}^{\mathrm{R}}\left(q_{i}, q_{j}\right)$ are continuous, there will be a mixed equilibrium. See Glicksberg (1952).
}

Table 3

Equilibria without commitment.

\begin{tabular}{|c|c|c|c|}
\hline & Parameter conditions & Period 1 & Period 2 \\
\hline$\left(X_{I I}^{n c}\right)$ & $0 \leq S_{1}<\frac{1}{2}-\frac{1}{2} \delta-\frac{1}{2} S_{2}$ & $\begin{array}{l}q_{1}^{\mathrm{nc}}=S_{1} \\
q_{2}^{\mathrm{nc}}=S_{2}\end{array}$ & $\begin{array}{l}r_{1}^{\mathrm{nc}}=0 \\
r_{2}^{\mathrm{nc}}=0\end{array}$ \\
\hline$\left(\mathrm{X}_{\mathrm{lm}}^{\mathrm{nc}}\right)$ & $\begin{array}{l}0 \leq S_{1}<\frac{1}{3}(1-\delta) \\
\frac{1}{2}-\frac{1}{2} \delta-\frac{1}{2} S_{1} \leq S_{2} \leq 1-\frac{1}{2} S_{1}\end{array}$ & $\begin{array}{l}q_{1}^{\mathrm{nc}}=S_{1} \\
q_{2}^{\mathrm{nc}}=\frac{1-S_{1}+2 \delta S_{2}-\delta}{2+2 \delta}\end{array}$ & $\begin{array}{l}r_{1}^{\mathrm{nc}}=0 \\
r_{2}^{\mathrm{nc}}=\frac{2 S_{2}-1+S_{1}+\delta}{2+2 \delta}\end{array}$ \\
\hline$\left(\mathrm{X}_{\mathrm{ml}}^{\mathrm{nc}}\right)$ & $\begin{array}{l}\frac{1}{2}-\frac{1}{2} \delta-\frac{1}{2} S_{2} \leq S_{1} \leq 1-\frac{1}{2} S_{2} \\
0 \leq S_{2}<\frac{1}{3}(1-\delta)\end{array}$ & $\begin{array}{l}q_{1}^{\mathrm{nc}}=\frac{1-S_{2}+2 \delta S_{1}-\delta}{2+2 \delta} \\
q_{2}^{\mathrm{nc}}=S_{2}\end{array}$ & $\begin{array}{l}r_{2}^{\mathrm{nc}}=\frac{2 S_{1}-1+S_{2}+\delta}{2+2 \delta} \\
r_{2}^{\mathrm{nc}}=0\end{array}$ \\
\hline$\left(X_{1 h}^{n c}\right)$ & $\begin{array}{l}0 \leq S_{1}<\frac{1}{3}(1-\delta) \\
S_{2}>1-\frac{1}{2} S_{1}\end{array}$ & $\begin{array}{l}q_{1}^{\mathrm{nc}}=S_{1} \\
q_{2}^{\mathrm{nc}}=\frac{1}{2}-\frac{1}{2} S_{1}\end{array}$ & $\begin{array}{l}r_{1}^{\mathrm{nc}}=0 \\
r_{2}^{\mathrm{nc}}=\frac{1}{2}\end{array}$ \\
\hline$\left(\mathrm{X}_{\mathrm{hl}}^{\mathrm{nc}}\right)$ & $S_{1}>1-\frac{1}{2} S_{2}$ & $q_{1}^{\mathrm{nc}}=\frac{1}{2}-\frac{1}{2} S_{2}$ & $r_{1}^{\mathrm{nc}}=\frac{1}{2}$ \\
\hline & $0 \leq S_{2}<\frac{1}{3}(1-\delta)$ & $q_{2}^{\mathrm{nc}}=S_{2}$ & $r_{2}^{\mathrm{nc}}=0$ \\
\hline$\left(\mathrm{X}_{\mathrm{mm}}^{\mathrm{nc}} a\right)$ & $\begin{array}{l}\frac{1}{3}(1-\delta) \leq S_{1} \leq \beta_{1} \\
\frac{1}{3}(1-\delta) \leq S_{2} \leq \beta_{2}\end{array}$ & $\begin{array}{l}q_{1}^{\mathrm{nc}}=\frac{1-\delta+3 \delta S_{1}}{3+3 \delta} \\
q_{2}^{\mathrm{nc}}=\frac{1-\delta+3 \delta S_{2}}{3+3 \delta}\end{array}$ & $\begin{array}{l}r_{1}^{\mathrm{nc}}=\frac{3 S_{1}-1+\delta}{3+3 \delta} \\
r_{2}^{\mathrm{nc}}=\frac{3 S_{2}-1+\delta}{3+3 \delta}\end{array}$ \\
\hline$\left(\mathrm{X}_{\mathrm{mm}}^{\mathrm{nc} \mathrm{b}}\right)$ & $\beta_{3}<S_{1} \leq 1-\frac{1}{2} S_{2}$ & & \\
\hline$\left(X_{\mathrm{mh}}^{\mathrm{nc}}\right)$ & $\begin{array}{l}\beta_{4}<S_{2} \leq 1-\frac{1}{2} S_{1} \\
\frac{1}{3}(1-\delta) \leq S_{1} \leq \frac{2}{3}-\frac{1}{9} \delta \\
S_{2}>\beta_{5}\end{array}$ & $\begin{aligned} q_{1}^{\mathrm{nc}} & =\frac{1-\delta+2 \delta S_{1}}{3+2 \delta} \\
q_{2}^{\mathrm{nc}} & =\frac{2+3 \delta-2 \delta S_{1}}{6+4 \delta}\end{aligned}$ & $\begin{array}{l}r_{1}^{\mathrm{nc}}=\frac{3 S_{1}-1+\delta}{3+2 \delta} \\
r_{2}^{\mathrm{nc}}=\frac{4+\delta-3 S_{1}}{6+4 \delta}\end{array}$ \\
\hline$\left(\mathrm{X}_{\mathrm{hm}}^{\mathrm{nc}}\right)$ & $\begin{array}{l}S_{1}>\beta_{6} \\
\frac{1}{3}(1-\delta) \leq S_{2} \leq \frac{2}{3}-\frac{1}{9} \delta\end{array}$ & $\begin{aligned} q_{1}^{\mathrm{nc}} & =\frac{2+3 \delta-2 \delta S_{2}}{6+4 \delta} \\
q_{2}^{\mathrm{nc}} & =\frac{1-\delta+2 \delta S_{2}}{3+2 \delta}\end{aligned}$ & $\begin{aligned} r_{1}^{\mathrm{nc}} & =\frac{4+\delta-3 S_{2}}{6+4 \delta} \\
r_{2}^{\mathrm{nc}} & =\frac{3 S_{2}-1+\delta}{3+2 \delta}\end{aligned}$ \\
\hline$\left(X_{m^{\prime} h}^{n c}\right)$ & $\begin{array}{l}\frac{2}{3}-\frac{1}{9} \delta<S_{1} \leq \frac{2}{3} \\
S_{2}>\beta_{7}\end{array}$ & $\begin{array}{l}q_{1}^{\mathrm{nc}}=S_{1}-\frac{1}{3} \\
q_{2}^{\mathrm{nc}}=\frac{2}{3}-\frac{1}{2} S_{1}\end{array}$ & $\begin{array}{l}r_{1}^{\mathrm{nc}}=\frac{1}{3} \\
r_{2}^{\mathrm{nc}}=\frac{1}{3}\end{array}$ \\
\hline$\left(X_{h^{\prime}}^{n c}\right)$ & $\begin{array}{l}S_{1}>\beta_{8} \\
\frac{2}{3}-\frac{1}{9} \delta<S_{2} \leq \frac{2}{3}\end{array}$ & $\begin{aligned} q_{1}^{\mathrm{nc}} & =\frac{2}{3}-\frac{1}{2} S_{2} \\
q_{2}^{\mathrm{nc}} & =S_{2}-\frac{1}{3}\end{aligned}$ & $\begin{aligned} r_{1}^{\mathrm{nc}} & =\frac{1}{3} \\
r_{2}^{\mathrm{nc}} & =\frac{1}{3}\end{aligned}$ \\
\hline$\left(\mathrm{X}_{\mathrm{hh}}^{\mathrm{nc}}\right)$ & $\begin{array}{l}S_{1}>\frac{2}{3} \\
S_{2}>\frac{2}{3}\end{array}$ & $\begin{array}{l}q_{1}^{\mathrm{nc}}=\frac{1}{3} \\
q_{2}^{\mathrm{nc}}=\frac{1}{3}\end{array}$ & $\begin{aligned} r_{1}^{\mathrm{nc}} & =\frac{1}{3} \\
r_{2}^{\mathrm{nc}} & =\frac{1}{3}\end{aligned}$ \\
\hline$\left(\mathrm{X}_{\varnothing}^{\mathrm{nc}}\right)$ & $\begin{array}{l}\text { All other values } \\
\text { of }\left(S_{1}, S_{2}, \delta\right)\end{array}$ & No equilibrium & \\
\hline
\end{tabular}

Explanation of the symbols

$\begin{array}{ll}\beta_{1} & \frac{7}{6}-S_{2}-\frac{1}{6} \delta+\frac{\sqrt{(1+\delta)\left(1+\frac{1}{2} \delta\right)}\left(\frac{5}{6}+\frac{1}{6} \delta-S_{2}\right)}{1+\delta}\left(\frac{7}{6}\right)\left(\frac{7}{6} \delta-S_{1}-\frac{1}{6} \delta+\frac{\left.\sqrt{1+\frac{1}{2}} \delta\right)}{1+\delta}\left(\frac{5}{6}\right)\right. \\ \beta_{2} & \frac{4+5 \frac{1}{2} \delta-\frac{1}{2} \delta^{2}-3 \delta S_{2}}{6+6 \delta} \\ \beta_{3} & \frac{4+5 \frac{1}{2} \delta-\frac{1}{2} \delta^{2}-3 \delta S_{1}}{6+6 \delta} \\ \beta_{4} & \frac{7+6 \frac{1}{2} \delta+\frac{3}{2} \delta^{2}-6 S_{1}-5 \delta S_{1}-\delta^{2} S_{1}+\left(5+5 \delta-2 \delta S_{1}\right) \sqrt{(1+\delta)\left(1+\frac{1}{2} \delta\right)}}{6+7 \delta+2 \delta^{2}+(6+4 \delta) \sqrt{(1+\delta)\left(1+\frac{1}{2} \delta\right)}} \\ \beta_{5} & \frac{7+6 \frac{1}{2} \delta+\frac{3}{2} \delta^{2}-6 S_{2}-5 \delta S_{2}-\delta^{2} S_{2}+\left(5+5 \delta-2 \delta S_{2}\right) \sqrt{(1+\delta)\left(1+\frac{1}{2} \delta\right)}}{6+7 \delta+2 \delta^{2}+(6+4 \delta) \sqrt{(1+\delta)\left(1+\frac{1}{2} \delta\right)}} \\ \beta_{6} & \frac{10+6 \delta-7 S_{1}-3 \delta S_{1}}{8+6 \delta} \\ \beta_{7} & \frac{10+6 \delta-7 S_{2}-3 \delta S_{2}}{8+6 \delta} \\ \beta_{8} & \end{array}$




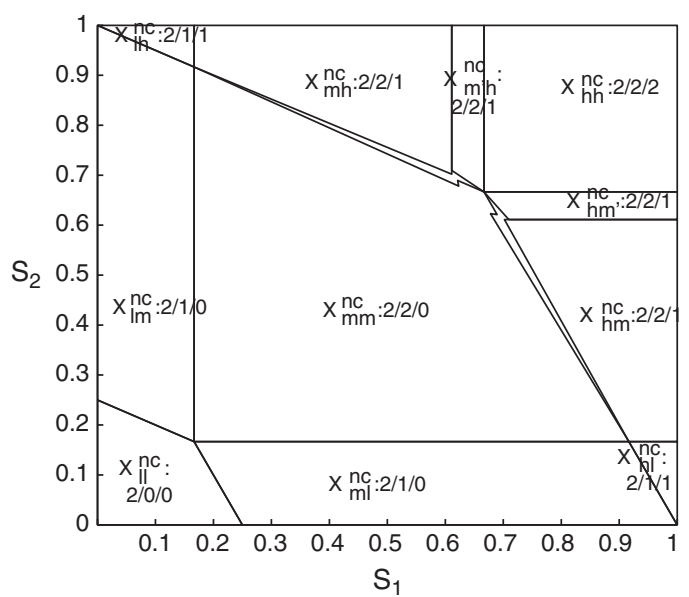

Fig. 3. Equilibrium outcome regions under non-commitment and the number of active firms in each period for $\delta=0.5$.

such that the equilibrium price strictly decreases over time. In particular, the equilibrium price strictly decreases over time if and only if $S_{i}<S_{j}$ and

$\frac{2-2 \delta}{3-2 \delta} \leq S_{i}<\frac{2}{3}-\frac{1}{9} \delta$,

$S_{j}>\frac{7+6 \frac{1}{2} \delta+\frac{3}{2} \delta^{2}-6 S_{i}-5 \delta S_{i}-\delta^{2} S_{i}+\left(5+5 \delta-2 \delta S_{i}\right) \sqrt{(1+\delta)\left(1+\frac{1}{2} \delta\right)}}{6+7 \delta+2 \delta^{2}+(6+4 \delta) \sqrt{(1+\delta)\left(1+\frac{1}{2} \delta\right)}}$

or

$\frac{2}{3}-\frac{1}{9} \delta<S_{i}<\frac{2}{3}$,

$S_{j}>\frac{10+6 \delta-7 S_{i}-3 \delta S_{i}}{8+6 \delta}$.

In those cases where prices decline over time, there is one firm with a large initial supply and one firm with a medium-sized stock. The larger firm faces no capacity constraint and chooses its optimal quantity of output for each period separately given the sales level of the smaller supplier. By contrast, the smaller firm is capacity-constrained in the second period (i.e., its second-period supply is less than $1 / 3$ ). To see why a price decline may occur in equilibrium, note that the larger firm has no incentive to adjust its sales strategy as it responds optimally in each period. In particular, as the smaller firm faces a capacity constraint in the second period, the larger firm is unable to induce a reduction in its rival's second-period sales. As with commitment, the smaller firm might be willing to transfer a part (or all) of its second-period supply to the first period. However, absent commitment, such a transfer will trigger a response by the larger firm. Specifically, the larger firm will increase its second-period sales, which leads to a lower second-period price. This reaction by the larger firm renders an adjustment in the smaller firm's sales strategy unprofitable.

As in the commitment setting, we next evaluate the impact of the level and allocation of initial stocks. Note that the profit function is continuous on the domain of $\left(S_{i}, S_{j}, \delta\right)$ for which an equilibrium exists. Using the derivatives of equilibrium profits, it is easily shown that an increase in stocks leads to higher profits within each equilibrium region. However, as the next result shows, an increase in initial supplies may still have an adverse effect on profits. Thus, equilibria may not be "destroy-proof".

Proposition 8. An increase in $S_{i}$, ceteris paribus, leads to a weak increase of firm i's equilibrium profit as long as the increase does not change the equilibrium outcome region. If an increase in $S_{i}$ does change the equilibrium outcome region, then there are combinations of $S_{i}, S_{j}$ and $\delta$ such that the increase in $S_{i}$ leads to a strict decrease in firm i's equilibrium profit.

Let us finally study the consequences of an increase in the difference of initial supplies.

Proposition 9. Given aggregate stock $S_{1}+S_{2}$, an increase in $\left|S_{1}-S_{2}\right|$ leads to a weak decrease in first-period aggregate equilibrium sales and a weak increase of first-period equilibrium price. Additionally, it leads to (i) a decrease in second-period aggregate equilibrium sales and an increase of second-period equilibrium price in regions $\mathrm{X}_{\mathrm{mh}}^{\mathrm{c}}$ and $\mathrm{X}_{\mathrm{hm}}^{\mathrm{c}}$ and (ii) an increase in second-period aggregate equilibrium sales and a decrease of second-period equilibrium price in regions $\mathrm{X}_{\mathrm{Im}}^{\mathrm{c}}$ and $\mathrm{X}_{\mathrm{ml}}^{\mathrm{c}}$. It has no effect on second-period aggregate equilibrium sales and second-period equilibrium price in the other regions.

As under commitment (see Proposition 3), a more asymmetric allocation of supplies leads to weakly higher first-period prices, whereas the impact on second-period prices is ambiguous.

\subsection{Comparison}

The above analysis reveals two major differences between strategic firm behavior under commitment and non-commitment. First, prices may decline over time only when firms do not commit to their sales strategies. Second, larger initial supplies may have a negative impact on firm profits only under non-commitment. Let us now have a closer look at how both regimes compare.

To begin, equilibrium sales are the same for both settings in quite a few cases.

Proposition 10. For each $\left(S_{1}, S_{2}, \delta\right) \in \mathrm{X}_{\mathrm{ll}}^{\mathrm{nc}} \cup \mathrm{X}_{\mathrm{lm}}^{\mathrm{nc}} \cup \mathrm{X}_{\mathrm{ml}}^{\mathrm{nc}} \cup \mathrm{X}_{\mathrm{lh}}^{\mathrm{nc}} \cup \mathrm{X}_{\mathrm{hl}}^{\mathrm{nc}} \cup \mathrm{X}_{\mathrm{mm}}^{\mathrm{nc}} \cup$ $\mathrm{X} \mathrm{hh}$, equilibrium sales under commitment and non-commitment coincide.

There always exists an equilibrium when $S_{1}=S_{2}$. As in this case $\left(S_{1}, S_{1}, \delta\right) \in \mathrm{X}_{l l}^{\mathrm{nc}} \cup \mathrm{X}_{\mathrm{mm}}^{\mathrm{nc}} \cup \mathrm{X}_{\mathrm{hh}}^{\mathrm{nc}}$ and $\left(S_{1}, S_{1}, \delta\right) \in \mathrm{X}_{\mathrm{ll}}^{\mathrm{c}} \cup \mathrm{X}_{\mathrm{mm}}^{\mathrm{c}} \cup \mathrm{X}_{\mathrm{hh}}^{\mathrm{c}}$, the next result follows immediately.

Corollary 11. If firms 1 and 2 are symmetric, then equilibrium sales under commitment and non-commitment coincide.

The story is different when $\left(S_{i}, S_{j}, \delta\right) \in \mathrm{X}_{\mathrm{mh}}^{\mathrm{nc}} \cup \mathrm{X}_{\mathrm{hm}}^{\mathrm{nc}} \cup \mathrm{X}_{\mathrm{m}^{\prime} \mathrm{h}}^{\mathrm{nc}} \cup \mathrm{X}_{\mathrm{hm}}^{\mathrm{nc}}$, i.e., when there is one firm with a large stock and one firm with a mediumsized stock. In these cases, the first-period equilibrium price under non-commitment weakly exceeds the first-period equilibrium price under commitment, whereas the opposite holds for second-period equilibrium prices.

Proposition 12. For each $\left(S_{1}, S_{2}, \delta\right) \notin \mathrm{X}_{\varnothing}^{n c}$, the first-period equilibrium price under non-commitment is weakly higher than the first-period equilibrium price under commitment and the second-period equilibrium price under non-commitment is weakly lower than the second-period equilibrium price under commitment. The opposite relationship holds for per-period aggregate sales.

The next result shows that the larger firm typically prefers not to commit to its sales strategy, whereas the smaller firm prefers commitment.

Proposition 13. For each $\left(S_{1}, S_{2} \delta\right) \notin \mathrm{X}_{\varnothing}^{n c}$, the change in equilibrium outcome from the commitment case to the non-commitment case is to the advantage of the larger firm and to the disadvantage of the smaller firm.

The intuition underlying this result is the following. Suppose that both sellers would choose their commitment equilibrium quantities under non-commitment. Given the sales strategy of the smaller firm, the larger firm has no incentive to deviate as it chooses the per-period optimal output level. By contrast, the smaller firm does 
have an incentive to adjust its supply strategy. Specifically, it will lower its first-period supply so as to be able to boost second-period sales. As the products are strategic substitutes, this in turn will induce the larger firm to reduce its second-period supply. This causes a price increase in both periods, which is beneficial for the smaller firm as it still sells all its products.

Yet, the larger firm will naturally anticipate this adjustment by increasing its first-period supply and, as we are outside region $\mathrm{X}_{\varnothing}^{\mathrm{nc}}$, another equilibrium is reached. Like for the smaller firm, the total amount of sales for the larger supplier is the same in both equilibria. Compared to the commitment setting, the smaller firm sells more of its stock in the second period, whereas the larger firm increases its first-period sales. By Proposition 12, we know that first-period prices are higher and second-period prices are lower absent commitment. Consequently, the larger firm typically prefers not to commit, whereas the smaller firm is better off under commitment.

\section{Welfare analysis}

In the previous section, we have derived optimal sales strategies under commitment and non-commitment. Let us now direct our attention to the welfare implications of both cases. As to welfare, questions of interest are: What is the impact of an increase in capacity on consumer surplus and total surplus? How does the allocation of available capacity affect consumer welfare and the welfare of society at large? How is welfare affected by whether or not firms commit to a particular sales strategy? In the following, we address these questions in turn.

To begin, note that in the current setting consumer and total surplus are given by, respectively,

$C S=\frac{1}{2}\left(q_{1}+q_{2}\right)^{2}+\frac{1}{2} \delta\left(r_{1}+r_{2}\right)^{2}$,

and

$T S=\left(q_{1}+q_{2}\right)\left(1-\frac{1}{2}\left(q_{1}+q_{2}\right)\right)+\delta\left(r_{1}+r_{2}\right)\left(1-\frac{1}{2}\left(r_{1}+r_{2}\right)\right)$.

Let us now first consider the effect of an increase in capacity on consumer welfare. The next proposition evaluates the impact of a growth in stocks on consumer surplus under commitment.

\section{Proposition 14. Commitment}

An increase in stock for at least one firm leads to a weakly higher equilibrium consumer surplus.

Thus, buyers typically benefit from an increase in the number of available products when firms commit to their sales strategy. By contrast, an increase in stocks may adversely affect consumer welfare absent commitment.

\section{Proposition 15. Non-commitment}

Within a given equilibrium outcome region, an increase in $S_{i}$, ceteris paribus, leads to a weakly higher equilibrium consumer surplus. For some combinations of $S_{i}, S_{j}$ and $\delta$, a strict increase in $S_{i}$ changes the equilibrium outcome region. This may lead to a strict fall in equilibrium consumer surplus.

These results reveal that consumers often gain from an increase in potential supply. A notable exception is when the increase in stock leads to a new equilibrium outcome region that is reached by moving through the non-equilibrium zone (see Fig. 3 ).

The next issue to consider is how the allocation of initial supplies affects welfare. By Propositions 3 and 9, we know that a larger difference in capacity may have different effects on second-period sales. It is therefore a priori unclear how an increase in $\left|S_{1}-S_{2}\right|$ affects consumer welfare. Yet, as the next result shows, this effect is unambiguously negative.
Proposition 16. For a given aggregate stock $S_{1}+S_{2}$, an increase in $\mid S_{1}-$ $S_{2}$ l leads to a weakly lower equilibrium consumer surplus.

Buyers commonly benefit from a more equal division of potential supplies. An increasing difference in production capacity allows the larger firm to more closely mimic a monopolist, which results in lower output and higher prices. Notice that this is independent of whether or not suppliers commit to their sales strategies.

As to social welfare, results are comparable. That is to say, an increase in capacity for at least one firm leads to a weakly higher equilibrium total surplus under commitment. Yet, if firms do not commit to their sales strategies, then a growth in stocks may induce a decrease in total welfare provided that it changes the equilibrium outcome region. Moreover, a more asymmetric allocation of available supplies leads to a weakly lower equilibrium total surplus.

A final issue to consider concerns the preferences of consumers, firms and the social planner. Do they prefer commitment to sales strategies or not? One would expect a priori that commitment has a mitigating effect on competition, which is typically to the advantage of firms and to the disadvantage of consumers and society as a whole. Indeed, given an unequal division of stocks, the smaller firm prefers commitment. Yet, the larger firm prefers non-commitment as it provides more opportunities for exploiting its power. Specifically, as shown in Proposition 12, non-commitment may result in a higher first-period price and a lower second-period price. Due to discounting, consumers therefore usually prefer commitment over non-commitment.

Proposition 17. For every $\left(S_{1}, S_{2}, \delta\right)$, such that $\left(S_{1}, S_{2}, \delta\right) \notin \mathrm{X}_{\varnothing}^{\mathrm{nc}}$ and $\delta \leq \frac{24}{25}$, consumers prefer commitment over non-commitment. If $\delta>\frac{24}{25}$, there are combinations of $\left(S_{1}, S_{2}, \delta\right)$ for which consumers prefer non-commitment.

The preference for commitment is even stronger for a social planner.

Proposition 18. Total surplus is higher under commitment than under non-commitment.

Our findings thus reveal that in situations where firms face an intertemporal capacity constraint, transparency of sales or flexible supply contracts can have a negative effect on welfare.

\section{Concluding remarks}

In a wide variety of industries, production precedes sales and supplies are (temporarily) given. In these types of situations, sellers may find themselves confronted with an intertemporal capacity constraint. The critical feature of such a constraint is that current supply decisions affect future profit opportunities; selling more today leaves less to sell tomorrow and vice versa. To gain understanding of the impact of intertemporal capacity constraints on strategic firm behavior and welfare, we have studied a two-period Cournot duopoly in which suppliers have a limited amount of products available. In analyzing optimal supply decisions, we have made a distinction between whether or not sellers commit to their sales strategies. Under commitment, strategies do not depend on the rival's realized sales, whereas without commitment sellers can adjust their supply decision after the first period.

Let us summarize some of our main findings. With commitment, there is a unique Nash equilibrium for any allocation of stocks and prices weakly increase over time. Absent commitment, a subgame perfect Nash equilibrium does not always exist and prices may decline over time. A more unequal division of initial supplies leads to higher first-period prices, but the effect on second-period prices is ambiguous. The difference between commitment and non-commitment is most pronounced when only one firm is capacity-constrained. In this case, the larger firm is better off absent commitment, whereas the smaller firm prefers commitment. Commitment to sales strategies is (almost always) beneficial for consumers and always leads to a higher total 
surplus. Thus, an increase in the transparency of sales and flexibility of supply contracts may adversely affect welfare in industries where firms cannot adjust production instantly to per-period demand.

We have addressed the impact of intertemporal capacity constraints in the simplest possible setting. Clearly, there are some potentially interesting extensions. For instance, we have limited our analysis to two periods and one may wonder whether our main findings still hold in a multi-period model. Another question of interest is how robust our results are to more general demand specifications. Moreover, it seems natural to explore similar issues in a setting where firms compete in price rather than quantity. As our analysis reveals, however, one may expect arduous calculations when pursuing these types of questions. The main challenge is therefore to find a more general model specification that is still analytically tractable. We leave this issue for future research.

\section{Appendix A. Proofs}

Proof of Proposition 1. For any given combination of $S_{1}, S_{2}$, and $\delta$, one can verify directly that $q_{1}^{\mathrm{c}}+q_{2}^{\mathrm{c}} \geq r_{1}^{\mathrm{c}}+r_{2}^{\mathrm{c}}$. Thus, aggregate sales in the first period weakly exceed aggregate sales in the second period and therefore the price in the first period is less than or equal to the price in the second period.

Proof of Proposition 2. The derivative of the equilibrium profit function of firm $i$ with respect to $S_{i}$ is non-negative in all equilibrium outcome regions and the profit function is continuous for all $\delta, S_{i}$, $S_{j} \geq 0$.

Proof of Proposition 3. Suppose that $S=S_{1}+S_{2}$ is fixed and assume $S_{2} \geq S_{1}$, which is without loss of generality. Note that this implies that $\left|S_{1}-S_{2}\right|$ increases when $S_{1}$ decreases and that $\left(S_{1}, S_{2}, \delta\right) \in \mathrm{X}_{\mathrm{Il}}^{\mathrm{c}} \cup \mathrm{X}_{\mathrm{Im}}^{\mathrm{c}} \cup$ $\mathrm{X}_{\mathrm{lh}}^{\mathrm{c}} \cup \mathrm{X}_{\mathrm{mm}}^{\mathrm{c}} \cup \mathrm{X}_{\mathrm{mh}}^{\mathrm{c}} \cup \mathrm{X}_{\mathrm{hh}}^{\mathrm{c}}$. In the following, let $Q_{\mathrm{ab}}$ denote aggregate sales in equilibrium region $\mathrm{X}_{\mathrm{ab}}$.

For first-period aggregate sales, we find that

$\begin{array}{ll}Q_{\mathrm{ll}}^{\mathrm{c}}=S, & \frac{\partial Q_{\mathrm{ll}}^{\mathrm{c}}}{\partial S_{1}}=0, \\ Q_{\mathrm{lm}}^{\mathrm{c}}=\frac{1-\delta+S_{1}+2 \delta S}{2+2 \delta}, & \frac{\partial Q_{\mathrm{lm}}^{\mathrm{c}}}{\partial S_{1}}=\frac{1}{2+2 \delta}>0, \\ Q_{\mathrm{lh}}^{\mathrm{c}}=\frac{1}{2}+\frac{1}{2} S_{1}, & \frac{\partial Q_{\mathrm{lh}}^{\mathrm{c}}}{\partial S_{1}}=\frac{1}{2}>0, \\ Q_{\mathrm{mm}}^{\mathrm{c}}=\frac{2-2 \delta+3 \delta S}{3+3 \delta}, & \frac{\partial Q_{\mathrm{mm}}^{\mathrm{c}}}{\partial S_{1}}=0, \\ Q_{\mathrm{mh}}^{\mathrm{c}}=\frac{4+2 \delta+3 \delta S_{1}}{6+6 \delta}, & \frac{\partial Q_{\mathrm{mh}}^{\mathrm{c}}}{\partial S_{1}}=\frac{3 \delta}{6+6 \delta}>0, \\ Q_{\mathrm{hh}}^{\mathrm{c}}=\frac{2}{3}, & \frac{\partial Q_{\mathrm{hh}}^{\mathrm{c}}}{\partial S_{1}}=0 .\end{array}$

Hence, an increase in $\left|S_{1}-S_{2}\right|$ leads to a weak decrease in firstperiod aggregate equilibrium sales and consequently to a weakly higher first-period equilibrium price.

For second-period aggregate sales, we find that

$$
\begin{array}{ll}
Q_{\mathrm{ll}}^{\mathrm{c}}=0, & \frac{\partial Q_{\mathrm{ll}}^{\mathrm{c}}}{\partial S_{1}}=0, \\
Q_{\mathrm{lm}}^{\mathrm{c}}=\frac{2 S-S_{1}-1+\delta}{2+2 \delta}, & \frac{\partial Q_{\mathrm{lm}}^{\mathrm{c}}}{\partial S_{1}}=-\frac{1}{2+2 \delta}<0, \\
Q_{\mathrm{lh}}^{\mathrm{c}}=\frac{1}{2}, & \frac{\partial Q_{\mathrm{lh}}^{c}}{\partial S_{1}}=0, \\
Q_{\mathrm{mm}}^{\mathrm{c}}=\frac{3 S-2+2 \delta}{3+3 \delta}, & \frac{\partial Q_{\mathrm{mm}}^{\mathrm{c}}}{\partial S_{1}}=0, \\
Q_{\mathrm{mh}}^{\mathrm{c}}=\frac{3 S_{1}+2+4 \delta}{6+6 \delta}, & \frac{\partial Q_{\mathrm{mh}}^{\mathrm{c}}}{\partial S_{1}}=\frac{3}{6+6 \delta}>0, \\
Q_{\mathrm{hh}}^{\mathrm{c}}=\frac{2}{3}, & \frac{\partial Q_{\mathrm{hh}}^{\mathrm{c}}}{\partial S_{1}}=0 .
\end{array}
$$

The effect of an increase in $\left|S_{1}-S_{2}\right|$ on second-period aggregate equilibrium sales and second-period equilibrium price thus depends on the equilibrium outcome region.

Proof of Lemma 4. First-period profit is given by $q_{i}\left(1-q_{i}-q_{j}\right)$, which is strictly decreasing in $q_{i}$ for $q_{i}>\frac{1}{2}-\frac{1}{2} q_{j}$ and in particular for $q_{i}>\frac{1}{2}$. A reduction in first-period sales implies an increase of potential supply in period 2. As Table 2 shows, firm $i$ 's second-period profit never decreases when its second-period stock increases. Consequently, firm $i$ would strictly increase its profits by choosing $q_{i}=\frac{1}{2}$ rather than $q_{i}>\frac{1}{2}$.

Proof of Theorem 5. Comparing the constraints in Table 3 shows that all regions are disjoint. Thus, each combination of $S_{i}, S_{j}$ and $\delta$ belongs to at most one equilibrium region. The Nash equilibrium of the reduced game is therefore unique for $\left(S_{i}, S_{j}, \delta\right)$ in regions $\mathrm{X}_{11}^{\mathrm{nc}}$ up to and including $\mathrm{X}_{\mathrm{hh}}^{\mathrm{nc}}$. The reduced game has no Nash equilibrium for $\left(S_{i}, S_{j}, \delta\right)$ belonging to region $\mathrm{X}_{\varnothing}^{\mathrm{nc}}$. Nash equilibria for the reduced game correspond one-to-one with the subgame perfect Nash equilibria of the entire game.

Proof of Theorem 6. It can be verified that for each $\delta$, the set of stock profiles $\left(S_{1}, S_{2}\right)$ such that $\left(S_{1}, S_{2}, \delta\right)$ belongs to region $\mathrm{X}_{\varnothing}^{\text {nc }}$ has a nonempty interior.

Proof of Proposition 7. By Proposition 1, price never decreases over time under commitment. A price decline under non-commitment is therefore only possible in regions where the non-commitment case is different from the commitment case, i.e., regions $X_{\mathrm{mh}}^{\mathrm{nc}}, \mathrm{X}_{\mathrm{hm}}^{\mathrm{nc}}, \mathrm{X}_{\mathrm{m}^{\prime} \mathrm{h}}^{\mathrm{nc}}$, and $X_{\mathrm{hm}^{\prime}}^{\mathrm{nc}}$. In these regions, one firm has a medium-sized stock and one firm has a large stock. Let $i$ be the smaller firm and let $j$ be the larger firm. In regions $\mathrm{X}_{\mathrm{mh}}^{\mathrm{nc}}$ and $\mathrm{X}_{\mathrm{hm}}^{\mathrm{nc}}$ it holds that

$$
\begin{aligned}
& \frac{1}{3}(1-\delta)<S_{i} \leq \frac{2}{3}-\frac{1}{9} \delta, \\
& S_{j}>\frac{7+6 \frac{1}{2} \delta+\frac{3}{2} \delta^{2}-6 S_{i}-5 \delta S_{i}-\delta^{2} S_{i}+\left(5+5 \delta-2 \delta S_{i}\right) \sqrt{(1+\delta)\left(1+\frac{1}{2} \delta\right)}}{6+7 \delta+2 \delta^{2}+(6+4 \delta) \sqrt{(1+\delta)\left(1+\frac{1}{2} \delta\right)}} .
\end{aligned}
$$

The total quantity sold in the first period is

$q_{i}^{\mathrm{nc}}+q_{j}^{\mathrm{nc}}=\frac{1-\delta+2 \delta S_{i}}{3+2 \delta}+\frac{2+3 \delta-2 \delta S_{i}}{6+4 \delta}=\frac{4+\delta+2 \delta S_{i}}{6+4 \delta}$.

The total quantity sold in the second period is

$r_{i}^{\mathrm{nc}}+r_{j}^{\mathrm{nc}}=\frac{3 S_{i}-1+\delta}{3+2 \delta}+\frac{4+\delta-3 S_{i}}{6+4 \delta}=\frac{3 S_{i}+2+3 \delta}{6+4 \delta}$.

Price strictly decreases from period 1 to period 2 when $4+$ $\delta+2 \delta S_{i}<3 S_{i}+2+3 \delta$, which is equivalent to $S_{i}>\frac{2-2 \delta}{3-2 \delta}$.

In regions $X_{\mathrm{m}^{\prime} \mathrm{h}}^{\mathrm{nc}}$ and $\mathrm{X}_{\mathrm{hm}^{\prime}}^{\mathrm{nc}}$ we have

$\frac{2}{3}-\frac{1}{9} \delta<S_{i} \leq \frac{2}{3}$

$S_{j}>\frac{10+6 \delta-7 S_{i}-3 \delta S_{i}}{8+6 \delta}$.

The total quantity sold in the first period is

$q_{i}^{\mathrm{nc}}+q_{j}^{\mathrm{nc}}=S_{i}-\frac{1}{3}+\frac{2}{3}-\frac{1}{2} S_{i}=\frac{1}{2} S_{i}+\frac{1}{3}$.

The total quantity sold in the second period is

$r_{i}^{\mathrm{nc}}+r_{j}^{\mathrm{nc}}=\frac{1}{3}+\frac{1}{3}=\frac{2}{3}$ 
Since $\frac{1}{2} S_{i}+\frac{1}{3}<\frac{2}{3}$ as long as $S_{i}<\frac{2}{3}$, price strictly decreases from period 1 to period 2 in these regions whenever $S_{i} \neq \frac{2}{3}$.

Proof of Proposition 8. The derivative of the equilibrium profit function with respect to $S_{i}$ is non-negative in every equilibrium region. The non-existence of an equilibrium for some combinations of $\left(S_{i}\right.$, $\left.S_{j}, \delta\right)$ makes it possible that a strict increase in $S_{i}$ leads to a strict decrease in the equilibrium profit of firm $i$. For instance, let $\delta=0.2$, $S_{j}=0.69824$, and

$S_{i}=\frac{7}{6}-S_{j}-\frac{1}{6} \delta+\frac{\sqrt{(1+\delta)\left(1+\frac{1}{2} \delta\right)}}{1+\delta}\left(\frac{5}{6}+\frac{1}{6} \delta-S_{j}\right) \approx 0.59634$.

These parameters correspond to a point on the upper boundary of region $\mathrm{X}_{\mathrm{mm}}^{\mathrm{nc}}$. The equilibrium profit of firm $i$ equals 0.12937 . Now suppose that $S_{i}$ increases to

$$
S_{i}^{\prime}=\frac{7+6 \frac{1}{2} \delta+\frac{3}{2} \delta^{2}-6 S_{j}-78 \delta S_{j}-2 \delta^{2} S_{j}+\left(5+5 \delta-6 S_{j}-4 \delta S_{j}\right) \sqrt{(1+\delta)\left(1+\frac{1}{2} \delta\right)}}{6+5 \delta+\delta^{2}+2 \delta \sqrt{(1+\delta)\left(1+\frac{1}{2} \delta\right)}}
$$

Our parameters now belong to region $\mathrm{X}_{\mathrm{mh}}^{\mathrm{nc}}$. Firm $i$ 's equilibrium profit equals 0.12751 .

Proof of Proposition 9. Suppose $S=S_{1}+S_{2}$ is fixed and $S_{2} \geq S_{1}$, which is without loss of generality. Thus, $\left|S_{1}-S_{2}\right|$ increases when $S_{1}$ decreases. Moreover, since $S_{2} \geq S_{1}$, it holds that $\left(S_{1}, S_{2}, \delta\right) \in \mathrm{X}_{11}^{\mathrm{nc}} \cup$ $\mathrm{X}_{\mathrm{lm}}^{\mathrm{nc}} \cup \mathrm{X}_{\mathrm{lh}}^{\mathrm{nc}} \cup \mathrm{X}_{\mathrm{mm}}^{\mathrm{nc}} \cup \mathrm{X}_{\mathrm{mh}}^{\mathrm{nc}} \cup \mathrm{X}_{\mathrm{m}^{\prime} \mathrm{h}}^{\mathrm{nc}} \cup \mathrm{X}_{\mathrm{hh}}^{\mathrm{nc}}$. As before, let $Q_{\mathrm{ab}}$ denote aggregate sales in equilibrium region $X_{a b}$. We then obtain the following

$$
\begin{array}{lll}
Q_{\mathrm{ll}}^{\mathrm{nc}}=S, & \frac{\partial Q_{11}^{\mathrm{nc}}}{\partial S_{1}}=0, \\
Q_{\mathrm{lm}}^{\mathrm{nc}}=\frac{1-\delta+S_{1}+2 \delta S}{2+2 \delta}, & \frac{\partial Q_{\mathrm{lm}}^{\mathrm{nc}}}{\partial S_{1}}=\frac{1}{2+2 \delta}>0, \\
Q_{\mathrm{lh}}^{\mathrm{nc}}=\frac{1}{2}+\frac{1}{2} S_{1}, & \frac{\partial Q_{\mathrm{lh}}^{\mathrm{nc}}}{\partial S_{1}}=\frac{1}{2}>0, \\
Q_{\mathrm{mm}}^{\mathrm{nc}}=\frac{2-2 \delta+3 \delta S}{3+3 \delta}, & \frac{\partial Q_{\mathrm{mm}}^{\mathrm{nc}}}{\partial S_{1}}=0, \\
Q_{\mathrm{mh}}^{\mathrm{nc}}=\frac{4+\delta+2 \delta S_{1}}{6+4 \delta}, & \frac{\partial Q_{\mathrm{mh}}^{\mathrm{nc}}}{\partial S_{1}}=\frac{2 \delta}{6+4 \delta}>0, \\
Q_{\mathrm{m} ' \mathrm{~h}}^{\mathrm{nc}}=\frac{1}{2} S_{1}+\frac{1}{3}, & \frac{\partial Q_{\mathrm{m} h \mathrm{~h}}^{\mathrm{nc}}}{\partial S_{1}}=\frac{1}{2}>0 . \\
Q_{\mathrm{hh}}^{\mathrm{nc}}=\frac{2}{3}, & \frac{\partial Q_{\mathrm{hh}}^{\mathrm{nc}}}{\partial S_{1}}=0 .
\end{array}
$$

In between regions $\mathrm{X}_{\mathrm{mm}}^{\mathrm{nc}}$ and $\mathrm{X}_{\mathrm{mh}}^{\mathrm{nc}}$ there is no equilibrium. Consider an increase in $S_{1}$ together with a decrease by the same magnitude in $S_{2}$ that leads to a move from region $X_{\mathrm{mh}}^{\mathrm{nc}}$ to region $\mathrm{X}_{\mathrm{mm}}^{\mathrm{nc}}$. In this case, it holds that $Q_{\mathrm{mm}}^{\mathrm{nc}}$ coincides with $Q_{\mathrm{mm}}^{\mathrm{c}}$ and

$Q_{\mathrm{mh}}^{\mathrm{nc}}=\frac{4+\delta+2 \delta S_{1}}{6+4 \delta}<\frac{4+2 \delta+3 \delta S_{1}}{6+6 \delta}=Q_{\mathrm{mh}}^{\mathrm{c}}$.

The desired result now follows from Proposition 3.

Between regions $X_{\mathrm{m}^{\prime \prime} \mathrm{h}}^{\mathrm{nc}}$ and $\mathrm{X}_{\mathrm{mm}}^{\mathrm{nc}}$ there is no equilibrium. Consider an increase in $S_{1}$ together with a decrease by the same magnitude in $S_{2}$ that leads to a move from region $X_{\mathrm{m}^{\prime} \mathrm{h}}^{\mathrm{nc}}$ to region $\mathrm{X}_{\mathrm{mm}}^{\mathrm{nc}}$. Again, it holds that $Q_{\mathrm{mm}}^{\mathrm{nc}}$ coincides with $Q_{\mathrm{mm}}^{\mathrm{c}}$, region $X_{\mathrm{m}^{\prime} \mathrm{h}}^{\mathrm{nc}}$ is a subset of region $\mathrm{X}_{\mathrm{mh}}^{\mathrm{c}}$, and

$Q_{\mathrm{m} ' \mathrm{~h}}^{\mathrm{nc}}=\frac{1}{2} S_{1}+\frac{1}{3} \leq \frac{4+2 \delta+3 \delta S_{1}}{6+6 \delta}=Q_{\mathrm{mh}}^{\mathrm{c}}$,

where $S_{1} \leq 2 / 3$ is used to derive the inequality sign. The desired result again follows from Proposition 3.
As to second-period aggregate sales, we obtain the following

$$
\begin{array}{ll}
Q_{\mathrm{ll}}^{\mathrm{nc}}=0, & \frac{\partial Q_{\mathrm{ll}}^{\mathrm{nc}}}{\partial S_{1}}=0, \\
Q_{\mathrm{lm}}^{\mathrm{nc}}=\frac{2 S-S_{1}-1+\delta}{2+2 \delta}, & \frac{\partial Q_{\mathrm{lm}}^{\mathrm{nc}}}{\partial S_{1}}=-\frac{1}{2+2 \delta}<0, \\
Q_{\mathrm{lh}}^{\mathrm{nc}}=\frac{1}{2}, & \frac{\partial Q_{\mathrm{lh}}^{\mathrm{nc}}}{\partial S_{1}}=0, \\
Q_{\mathrm{mm}}^{\mathrm{nc}}=\frac{3 S-2+2 \delta}{3+3 \delta}, & \frac{\partial Q_{\mathrm{mm}}^{\mathrm{nc}}}{\partial S_{1}}=0, \\
Q_{\mathrm{mh}}^{\mathrm{nc}}=\frac{3 S_{1}+2+3 \delta}{6+4 \delta}, & \frac{\partial Q_{\mathrm{mh}}^{\mathrm{nc}}}{\partial S_{1}}=\frac{3}{6+4 \delta}>0, \\
Q_{\mathrm{m} h \mathrm{n}}^{\mathrm{nc}}=\frac{2}{3}, & \frac{\partial Q_{\mathrm{m} h}^{\mathrm{nc}}}{\partial S_{1}}=0, \\
Q_{\mathrm{hh}}^{\mathrm{nc}}=\frac{2}{3}, & \frac{\partial Q_{\mathrm{hh}}^{\mathrm{nc}}}{\partial S_{1}}=0 .
\end{array}
$$

Proof of Proposition 10. From the constraints that define the various regions it follows that $\mathrm{X}_{\mathrm{ll}}^{\mathrm{nc}} \subseteq \mathrm{X}_{\mathrm{ll}}^{\mathrm{c}}, \mathrm{X}_{\mathrm{lm}}^{\mathrm{nc}} \subseteq \mathrm{X}_{\mathrm{lm}}^{\mathrm{c}}, \mathrm{X}_{\mathrm{ml}}^{\mathrm{nc}} \subseteq \mathrm{X}_{\mathrm{ml}}^{\mathrm{c}}, \mathrm{X}_{\mathrm{lh}}^{\mathrm{nc}} \subseteq \mathrm{X}_{\mathrm{lh}}^{\mathrm{c}}, \mathrm{X}_{\mathrm{hl}}^{\mathrm{nc}} \subseteq \mathrm{X}_{\mathrm{hl}}^{\mathrm{c}}$, $X_{\mathrm{mm}}^{\mathrm{nc}} \subseteq \mathrm{X}_{\mathrm{mm}}^{\mathrm{c}}$ and $\mathrm{X}_{\mathrm{hh}}^{\mathrm{nc}} \subseteq \mathrm{X}_{\mathrm{hh}}^{\mathrm{c}}$. The equilibrium sales in regions $\mathrm{X}_{\mathrm{ll}}^{\mathrm{nc}}, \mathrm{X}_{\mathrm{lm}}^{\mathrm{nc}}, \mathrm{X}_{\mathrm{ml}}^{\mathrm{nc}}$, $\mathrm{X}_{\mathrm{lh}}^{\mathrm{nc}}, \mathrm{X}_{\mathrm{hl}}^{\mathrm{nc}}, \mathrm{X}_{\mathrm{mm}}^{\mathrm{nc}}$, and $\mathrm{X}_{\mathrm{hh}}^{\mathrm{nc}}$ coincide with the equilibrium sales in, respectively, region $X_{\mathrm{ll}}^{\mathrm{c}}, \mathrm{X}_{\mathrm{lm}}^{\mathrm{c}}, \mathrm{X}_{\mathrm{ml}}^{\mathrm{c}}, \mathrm{X}_{\mathrm{lh}}^{\mathrm{c}}, \mathrm{X}_{\mathrm{hl}}^{\mathrm{c}}, \mathrm{X}_{\mathrm{mm}}^{\mathrm{c}}$ and $\mathrm{X}_{\mathrm{hh}}^{\mathrm{c}}$.

Proof of Proposition 12. We assume without loss of generality that $S_{2} \geq S_{1}$. Whenever there is a change in the equilibrium price, $\left(S_{1}, S_{2}\right.$, $\delta$ ) belongs to region $\mathrm{X}_{\mathrm{mh}}^{\mathrm{c}}$. In region $\mathrm{X}_{\mathrm{mh}}^{\mathrm{c}}$, prices in the first and second periods are respectively

$p_{1}^{c}=\frac{2+4 \delta-3 \delta S_{1}}{6+6 \delta}$ and $p_{2}^{c}=\frac{4+2 \delta-3 S_{1}}{6+6 \delta}$.

Furthermore, $\left(S_{1}, S_{2}, \delta\right)$ belongs to region $\mathrm{X}_{\mathrm{mh}}^{\mathrm{nc}}$ or $\mathrm{X}_{\mathrm{m}}^{\mathrm{nc} h}$. In region $\mathrm{X}_{\mathrm{mh}}^{\mathrm{nc}}$, prices are

$p_{1}^{\mathrm{nc}}=\frac{2+3 \delta-2 \delta S_{1}}{6+4 \delta}$ and $p_{2}^{\mathrm{nc}}=\frac{4+\delta-3 S_{1}}{6+4 \delta}$

and in region $\mathrm{X}_{\mathrm{m} \prime \mathrm{h}}^{\mathrm{nc}}$, prices are

$p_{1}^{\mathrm{nc}}=\frac{2}{3}-\frac{1}{2} S_{1}$ and $p_{2}^{\mathrm{nc}}=\frac{1}{3}$.

In region $X_{\mathrm{mh}}^{\mathrm{c}}$, we have $(1-\delta) / 3<S_{1} \leq \frac{2}{3}$ from which it follows that $p_{1}^{\mathrm{c}} \leq p_{1}^{\mathrm{nc}}$ and $p_{2}^{\mathrm{c}} \geq p_{2}^{\mathrm{nc}}$.

Proof of Proposition 13. Assume without loss of generality that $S_{2} \geq S_{1}$. Whenever there is a change in the equilibrium outcome, it holds that $\left(S_{1}, S_{2}, \delta\right)$ belongs to region $\mathrm{X}_{\mathrm{mh}}^{\mathrm{c}}$. Firm 2 has profits equal to

$\Pi_{2}^{\mathrm{c}}=\left(\frac{2+4 \delta-3 \delta S_{1}}{6+6 \delta}\right)^{2}+\delta\left(\frac{4+2 \delta-3 S_{1}}{6+6 \delta}\right)^{2}$.

Moreover, $\left(S_{1}, S_{2}, \delta\right)$ belongs to region $\mathrm{X}_{\mathrm{mh}}^{\mathrm{nc}}$ or region $\mathrm{X}_{\mathrm{m} \text { 'h }}^{\mathrm{nc}}$. In region $\mathrm{X}_{\mathrm{mh}}^{\mathrm{nc}}$, firm 2 has profits equal to

$\Pi_{2}^{\mathrm{nc}}=\left(\frac{2+3 \delta-2 \delta S_{1}}{6+4 \delta}\right)^{2}+\delta\left(\frac{4+\delta-3 S_{1}}{6+4 \delta}\right)^{2}$.

In region $\mathrm{X}_{\mathrm{m}}^{\mathrm{nc} h}$, profits of firm 2 are given by

$\Pi_{2}^{\mathrm{nc}}=\frac{4}{9}+\frac{1}{9} \delta-\frac{2}{3} S_{1}+\frac{1}{4}\left(S_{1}\right)^{2}$.

We have that $S_{1} \leq \frac{2}{3}$ in all these regions, from which it follows that $\Pi_{2}^{\mathrm{nc}} \geq \Pi_{2}^{\mathrm{c}}$.

Analogous calculations yield the opposite relation for the profits of firm 1. 
Proof of Proposition 14. It follows directly from the equilibrium outcomes that per-period sales weakly increase in $S_{1}$ and $S_{2}$.

Proof of Proposition 15. It follows directly from the equilibrium outcomes that per-period sales weakly increase in $S_{1}$ and $S_{2}$ in all equilibrium outcome regions. To illustrate that an increase in stocks may adversely affect consumer surplus, consider $\delta, S_{i}, S_{i}^{\prime}$ and $S_{j}$ as defined in the proof of Proposition 8. Equilibrium consumer surplus for $\delta, S_{i}, S_{j}$ is given by

$C S_{\mathrm{mm}}^{\mathrm{nc}} \approx 0.25818$.

An increase from $S_{i}$ to $S_{i}^{\prime}$ results in an equilibrium consumer surplus of $C S_{\mathrm{mh}}^{\mathrm{nc}} \approx 0.25600$.

Proof of Proposition 16. We will show that for given aggregate stock $S=S_{1}+S_{2}$, an increase in $\left|S_{1}-S_{2}\right|$ leads to a weakly lower equilibrium consumer surplus under commitment and non-commitment.

Commitment:

Except for regions $\mathrm{X}_{\mathrm{Im}}^{\mathrm{c}}$ and $\mathrm{X}_{\mathrm{m}}^{\mathrm{c}}$, Proposition 3 implies a weak decrease in sales in both periods when $\left|S_{1}-S_{2}\right|$ increases and therefore a weak decrease in consumer surplus.

Consider some $\left(S_{1}, S_{2}, \delta\right)$ in region $\mathrm{X}_{\mathrm{lm}}^{\mathrm{c}}$ or $\mathrm{X}_{\mathrm{ml}}^{\mathrm{c}}$. Assume without loss of generality that $S_{2} \geq S_{1}$, so $\left|S_{1}-S_{2}\right|$ increases if $S_{1}$ decreases. Then $\left(S_{1}, S_{2}, \delta\right)$ belongs to region $\mathrm{X}_{\mathrm{lm}}^{\mathrm{c}}$. Consumer surplus is given by

$\frac{1}{2}\left(\frac{1-\delta+S_{1}+2 \delta S}{2+2 \delta}\right)^{2}-\frac{1}{2} \delta\left(\frac{2 S-S_{1}-1+\delta}{2+2 \delta}\right)^{2}$.

The derivative of the above expression with respect to $S_{1}$ is

$\frac{1-\delta+S_{1}+2 \delta S}{(2+2 \delta)^{2}}+\delta \frac{2 S-S_{1}-1+\delta}{(2+2 \delta)^{2}}$,

which is easily shown to be non-negative.

Non-commitment:

First note that, following Proposition 10, this proposition holds for $\left|S_{1}-S_{2}\right|$ as long as $\left(S_{1}, S_{2}, \delta\right) \notin \mathrm{X}_{\mathrm{mh}}^{\mathrm{nc}} \cup \mathrm{X}_{\mathrm{hm}}^{\mathrm{nc}} \cup \mathrm{X}_{\mathrm{m}{ }^{\prime} \mathrm{h}}^{\mathrm{nc}} \cup \mathrm{X}_{\mathrm{hm} \mathrm{m}^{\prime}}^{\mathrm{nc}}$. Next, suppose without loss of generality that $S_{2} \geq S_{1}$. Thus, $\left|S_{1}-S_{2}\right|$ increases if $S_{1}$ decreases. Proposition 9 implies a weak decrease in sales in both periods when $\left|S_{1}-S_{2}\right|$ increases and therefore a weak decrease in consumer surplus for regions $X_{\mathrm{m}^{\prime} \mathrm{h}}^{\mathrm{nc}}$ and $\mathrm{X}_{\mathrm{mh}}^{\mathrm{nc}}$. The remaining cases to check are those where a decrease in $S_{1}$ changes the equilibrium outcome from a point in $X_{\mathrm{mm}}^{\mathrm{nc}}$ to a point in $X_{\mathrm{mh}}^{\mathrm{nc}}$ or from $X_{\mathrm{mm}}^{\mathrm{nc}}$ to $X_{\mathrm{m} ' \mathrm{~h}}^{\mathrm{nc}}$.

Let $c=S_{1}+S_{2}$, where $c$ is a constant. Consumer surplus in region $\mathrm{X}_{\mathrm{mh}}^{\mathrm{nc}}$ and region $\mathrm{X}_{\mathrm{m}}^{\mathrm{nc}} \mathrm{h}$ is

$C S_{\mathrm{mh}}^{\mathrm{nc}}=\frac{1}{2}\left(\frac{4+\delta+2 \delta S_{1}}{6+4 \delta}\right)^{2}+\frac{1}{2} \delta\left(\frac{3 S_{1}+2+3 \delta}{6+4 \delta}\right)^{2}$,

$C S_{\mathrm{m}^{\prime} \mathrm{h}}^{\mathrm{nc}}=\frac{1}{2}\left(\frac{1}{2} S_{1}+\frac{1}{3}\right)^{2}+\frac{2}{9} \delta$,

and in region $\mathrm{X}_{\mathrm{mm}}^{\mathrm{nc}}$

$C S_{\mathrm{mm}}^{\mathrm{nc}}=\frac{1}{2}\left(\frac{2-2 \delta+3 \delta c}{3+3 \delta}\right)^{2}+\frac{1}{2} \delta\left(\frac{3 c-2+2 \delta}{3+3 \delta}\right)^{2}$.

As mentioned, consumer surplus in regions $X_{\mathrm{mh}}^{\mathrm{nc}}$ and $\mathrm{X}_{\mathrm{m} \prime \mathrm{h}}^{\mathrm{nc}}$ increases with $S_{1}$, for fixed $c$. In region $X_{\mathrm{mm}}^{\mathrm{nc}}$, consumer surplus doesn't change if $S_{1}$ changes, for fixed $c$. This implies that, if $C S_{\mathrm{mh}}^{\mathrm{nc}} \leq C S_{\mathrm{mm}}^{\mathrm{nc}}$ for any $\left(S_{1}, S_{2}, \delta\right) \in\left\{\left(S_{1}, S_{2}, \delta\right) \mid S_{2}=\beta_{5}, \frac{1}{3}(1-\delta) \leq S_{1} \leq \frac{2}{3}-\frac{1}{9} \delta\right\}$, consumer surplus decreases when an increase in $S_{1}$ changes the equilibrium outcome from region $X_{\mathrm{mh}}^{\mathrm{nc}}$ to $\mathrm{X}_{\mathrm{mm}}^{\mathrm{nc}}$. Indeed, calculations show that $C S_{\mathrm{mh}}^{\mathrm{nc}} \leq C S_{\mathrm{mm}}^{\mathrm{nc}}$ for these values of $\left(S_{1}, S_{2}, \delta\right)$. Also, it implies that when $C S_{\mathrm{m}^{\prime h}}^{\mathrm{nc}} \leq C S_{\mathrm{mm}}^{\mathrm{nc}}$ for any $\left(S_{1}, S_{2}, \delta\right) \in\left\{\left(S_{1}, S_{2}, \delta\right) \mid S_{2}=\beta_{7}, \frac{2}{3}-\frac{1}{9} \delta<S_{1} \leq \frac{2}{3}\right\}$, consumer surplus decreases when an increase in $S_{1}$ changes the equilibrium outcome from region $\mathrm{X}_{\mathrm{m} \prime \mathrm{h}}^{\mathrm{nc}}$ to $\mathrm{X}_{\mathrm{mm}}^{\mathrm{nc}}$.
Proof of Proposition 17. Assume without loss of generality that $S_{2} \geq S_{1}$. Whenever there is a change in consumer surplus between settings, $\left(S_{1}, S_{2}, \delta\right)$ belongs to region $\mathrm{X}_{\mathrm{mh}}^{\mathrm{c}}$, and to Region $\mathrm{X}_{\mathrm{mh}}^{\mathrm{nc}}$ or $\mathrm{X}_{\mathrm{m}^{\prime} \mathrm{h}}^{\mathrm{nc}}$. Consumer surplus in regions $\mathrm{X}_{\mathrm{mh}}^{\mathrm{c}}, \mathrm{X}_{\mathrm{mh}}^{\mathrm{nc}}$ and $\mathrm{X}_{\mathrm{m}}^{\mathrm{nc} h}$ is respectively

$C S_{\mathrm{mh}}^{\mathrm{c}}=\left(\frac{4+2 \delta+3 \delta S_{1}}{6+6 \delta}\right)^{2}+\delta\left(\frac{3 S_{1}+2+4 \delta}{6+6 \delta}\right)^{2}$,
$C S_{\mathrm{mh}}^{\mathrm{nc}}=\left(\frac{4+\delta+2 \delta S_{1}}{6+4 \delta}\right)^{2}+\delta\left(\frac{3 S_{1}+2+3 \delta}{6+4 \delta}\right)^{2}$,
$C S_{\mathrm{m}^{\prime} \mathrm{h}}^{\mathrm{nc}}=\left(\frac{1}{2} S_{1}+\frac{1}{3}\right)^{2}+\frac{4}{9} \delta$.

For region $\mathrm{X}_{\mathrm{mh}}^{\mathrm{nc}}$ and $\mathrm{X}_{\mathrm{m}^{\prime} \mathrm{h}}^{\mathrm{nc}}$, it holds respectively that $\frac{1}{3}(1-\delta) \leq S_{i} \leq$ $\frac{2}{3}-\frac{1}{9} \delta$ and $\frac{2}{3}-\frac{1}{9} \delta<S_{i} \leq \frac{2}{3}$. Now,

$C S_{\mathrm{mh}}^{\mathrm{c}} \geq C S_{\mathrm{mh}}^{\mathrm{nc}}$ for $S_{i} \in\left[\frac{1}{3}(1-\delta), \frac{24-7 \delta-17 \delta^{2}}{3 \delta}\right]$

and

$C S_{\mathrm{mh}}^{\mathrm{c}} \geq C S_{\mathrm{m}^{\prime} \mathrm{h}}^{\mathrm{nc}}$ for $S_{i} \in\left[-2+\frac{8}{3} \delta, \frac{2}{3}\right]$

It holds that

$\frac{24-7 \delta-17 \delta^{2}}{3 \delta} \geq \frac{2}{3}-\frac{1}{9} \delta$

if and only if $\delta \leq \frac{24}{25}$ and

$-2+\frac{8}{3} \delta \leq \frac{2}{3}-\frac{1}{9} \delta$

if and only if $\delta \leq \frac{24}{25}$. Thus, for $\delta \leq \frac{24}{25}$, consumers prefer commitment to non-commitment.

Proof of Proposition 18. Assume without loss of generality that $S_{2} \geq S_{1}$. Whenever there is a change in total surplus between the commitment and the non-commitment setting, $\left(S_{1}, S_{2}, \delta\right)$ belongs to region $X_{\mathrm{mh}}^{\mathrm{c}}$, and to region $\mathrm{X}_{\mathrm{mh}}^{\mathrm{nc}}$ or $\mathrm{X}_{\mathrm{m} \prime \mathrm{h}}^{\mathrm{nc}}$. Total surplus in regions $\mathrm{X}_{\mathrm{mh}}^{\mathrm{c}}$, $\mathrm{X}_{\mathrm{mh}}^{\mathrm{nc}}$ and $\mathrm{X}_{\mathrm{m} / \mathrm{h}}^{\mathrm{nc}}$ is respectively given by

$$
\begin{aligned}
& T S_{\mathrm{mh}}^{\mathrm{c}}=\left(\frac{4+2 \delta+3 \delta S_{1}}{6+6 \delta}\right)\left(1-\frac{1}{2}\left(\frac{4+2 \delta+3 \delta S_{1}}{6+6 \delta}\right)\right)+\delta\left(\frac{3 S_{1}+2+4 \delta}{6+6 \delta}\right)\left(1-\frac{1}{2}\left(\frac{3 S_{1}+2+4 \delta}{6+6 \delta}\right)\right), \\
& T S_{\mathrm{mh}}^{\mathrm{nc}}=\left(\frac{4+\delta+2 \delta S_{1}}{6+4 \delta}\right)\left(1-\frac{1}{2}\left(\frac{4+\delta+2 \delta S_{1}}{6+4 \delta}\right)\right)+\delta\left(\frac{3 S_{1}+2+3 \delta}{6+4 \delta}\right)\left(1-\frac{1}{2}\left(\frac{3 S_{1}+2+3 \delta}{6+4 \delta}\right)\right), \\
& T S_{\mathrm{mh}}^{\mathrm{nc}}=\left(\frac{1}{2} S_{1}+\frac{1}{3}\right)\left(1-\frac{1}{2}\left(\frac{1}{2} S_{1}+\frac{1}{3}\right)\right)+\delta\left(\frac{2}{3}\right)\left(1-\frac{1}{3}\right) .
\end{aligned}
$$

For region $X_{h m}^{\mathrm{nc}}$ and region $\mathrm{X}_{\mathrm{hm}}^{\mathrm{nc}}$, it holds respectively that $\frac{1}{3}(1-\delta) \leq$ $S_{i} \leq \frac{2}{3}-\frac{1}{9} \delta$ and $\frac{2}{3}-\frac{1}{9} \delta<S_{i} \leq \frac{2}{3}$. Now,

$T S_{\mathrm{mh}}^{\mathrm{nc}} \geq T S_{\mathrm{mh}}^{\mathrm{c}}$ if and only if $S_{1} \in\left[\frac{-12+5 \delta+7 \delta^{2}}{3 \delta}, \frac{1}{3}(1-\delta)\right]$

and

$T S_{\mathrm{m} \prime \mathrm{h}}^{\mathrm{nc}} \geq T S_{\mathrm{mh}}^{\mathrm{c}}$ if and only if $S_{1} \in\left[\frac{2}{3}, 2-\frac{4}{3} \delta\right]$.

Hence, for $S_{1} \in\left[\frac{1}{3}(1-\delta), \frac{2}{3}\right]$, total surplus is highest in the commitment setting. 


\section{Appendix B. Reduced best response correspondence}

We derive the reduced best response correspondence of firm $i$ for the non-commitment case. To keep the appendix within reasonable length, we have omitted the derivation of second-order conditions. In accordance with Lemma 4, we can restrict our analysis to best responses against $q_{j} \leq \frac{1}{2}$. We distinguish three cases:
(A) $q_{j}<S_{j}-\frac{1}{2}$,
(B) $S_{j}-\frac{1}{2} \leq q_{j}<S_{j}-\frac{1}{3}$
(C) $S_{j}-\frac{1}{3} \leq q_{j} \leq S_{j}$. firm $j$.

These three cases correspond to the three cases of residual stock $T_{j}=S_{j}-q_{j}$ of firm $j$ with qualitatively different second-period behavior of
(A) $q_{j}<S_{j}-\frac{1}{2}$

Using the reduced profit function (2), for $0 \leq q_{i}<S_{i}-\frac{1}{3}$, profit is given by $\left(\mathrm{Y}_{\mathrm{hh}}\right.$ ), and for $S_{i}-\frac{1}{3} \leq q_{i} \leq S_{i}$, profit is given by ( $\mathrm{Y}_{\mathrm{lh}}$ ). Taking the unrestricted first-order condition of the profit function in $\left(\mathrm{Y}_{\mathrm{hh}}\right)$ and $\left(\mathrm{Y}_{\mathrm{lh}}\right)$ and solving for $q_{i}$ results in $q_{i}^{\text {hh }}$ and $q_{i}^{\text {lh }}$ given by

$$
\begin{aligned}
q_{i}^{\mathrm{hh}} & =\frac{1}{2}-\frac{1}{2} q_{j}, \\
q_{i}^{\mathrm{lh}} & =\frac{1-q_{j}-\frac{1}{2} \delta+\delta S_{i}}{2+\delta} .
\end{aligned}
$$

It holds that $q_{i}^{\text {hh }} \in\left[0, S_{i}-\frac{1}{3}\right)$ if and only if $\frac{5}{6}-\frac{1}{2} q_{j}<S_{i}$. Similarly, it holds that $q_{i}^{\text {lh }} \in\left[S_{i}-\frac{1}{3}, S_{i}\right]$ if and only if $\frac{1}{2}-\frac{1}{2} q_{j}-\frac{1}{4} \delta \leq S_{i} \leq \frac{5}{6}-\frac{1}{12} \delta-\frac{1}{2} q_{j}$. We therefore find that the reduced best response $q_{i}^{*}$ of player 1 to $q_{j}$ is given by

$$
q_{i}^{*}= \begin{cases}S_{i}, & \text { if } 0 \leq S_{i}<\frac{1}{2}-\frac{1}{2} q_{j}-\frac{1}{4} \delta, \\ \frac{1-q_{j}-\frac{1}{2} \delta+\delta S_{i}}{2+\delta}, & \text { if } \frac{1}{2}-\frac{1}{2} q_{j}-\frac{1}{4} \delta \leq S_{i} \leq \frac{5}{6}-\frac{1}{12} \delta-\frac{1}{2} q_{j}, \\ S_{i}-\frac{1}{3}, & \text { if } \frac{5}{6}-\frac{1}{12} \delta-\frac{1}{2} q_{j}<S_{i} \leq \frac{5}{6}-\frac{1}{2} q_{j}, \\ \frac{1}{2}-\frac{1}{2} q_{j}, & \text { if } \frac{5}{6}-\frac{1}{2} q_{j}<S_{i} .\end{cases}
$$

(B) $S_{j}-\frac{1}{2} \leq q_{j}<S_{j}-\frac{1}{3}$

It follows from the reduced profit function (2) that, for $0 \leq q_{i}<S_{i}-\frac{1}{3}$, profit is given by $\left(\mathrm{Y}_{\mathrm{hh}}\right)$, for $S_{i}-\frac{1}{3} \leq q_{i}<2 T_{j}-1+S_{i}$, profit is given by ( $\mathrm{Y}_{\mathrm{lh}}$ ), and for $2 T_{j}-1+S_{i} \leq q_{i} \leq S_{i}$, profit is given by $\left(\mathrm{Y}_{\mathrm{ll}}\right)$. Taking the unrestricted first-order condition of the reduced profit function in ( $\left.\mathrm{Y}_{\mathrm{hh}}\right)$, ( $\left.\mathrm{Y}_{\mathrm{lh}}\right)$ and $\left(\mathrm{Y}_{11}\right)$ and solving for $q_{i}$ results in $q_{i}^{\mathrm{hh}}, q_{i}^{\mathrm{lh}}$, and $q_{i}^{\mathrm{ll}}$ given by

$$
\begin{aligned}
& q_{i}^{\text {hh }}=\frac{1}{2}-\frac{1}{2} q_{j}, \\
& q_{i}^{\text {lh }}=\frac{1-q_{j}-\frac{1}{2} \delta+\delta S_{i}}{2+\delta}, \\
& q_{i}^{\text {ll }}=\frac{1-q_{j}+2 \delta S_{i}-\delta+\delta T_{j}}{2+2 \delta} .
\end{aligned}
$$

It holds that $q_{i}^{\mathrm{hh}} \in\left[0, S_{i}-\frac{1}{3}\right)$ if and only if $\frac{5}{6}-\frac{1}{2} q_{j}<S_{i}$. Similarly, it holds that $q_{i}^{\mathrm{lh}} \in\left[\max \left\{0, S_{i}-\frac{1}{3}\right\}, 2 T_{j}-1+S_{i}\right)$ if and only if $\underline{S}_{i}^{\mathrm{lh}}<S_{i} \leq \bar{S}_{i}^{\mathrm{lh}}$, where

$$
\begin{aligned}
\underline{S}_{i}^{\mathrm{lh}} & =\frac{3}{2}+\frac{1}{4} \delta-\frac{1}{2} q_{j}-(2+\delta) T_{j}, \\
\bar{S}_{i}^{\mathrm{lh}} & =\frac{5}{6}-\frac{1}{12} \delta-\frac{1}{2} q_{j} .
\end{aligned}
$$


The requirement $q_{i}^{\mathrm{lh}} \geq 0$ is not binding, since $q_{j} \leq \frac{1}{2}$ implies $q_{i}^{\mathrm{lh}}$ is positive. It holds that $q_{i}^{\mathrm{ll}} \in\left[\max \left\{0,2 T_{j}-1+S_{i}\right\}, S_{i}\right]$ if and only if $\max \left\{\underline{S}_{i}^{\mathrm{lla}}, \underline{S}_{i}^{\mathrm{llb}}\right\} \leq S_{i} \leq \bar{S}_{i}^{\mathrm{ll}}$, where

$$
\begin{aligned}
& \underline{S}_{i}^{\mathrm{lla}}=\frac{1}{2 \delta}\left(q_{j}-1+\delta-\delta T_{j}\right), \\
& \underline{S}_{i}^{\mathrm{llb}}=\frac{1}{2}\left(1-\delta-q_{j}+\delta T_{j}\right), \\
& \bar{S}_{i}^{\mathrm{ll}}=\frac{3}{2}+\frac{1}{2} \delta-\frac{1}{2} q_{j}-\left(2+\frac{3}{2} \delta\right) T_{j} .
\end{aligned}
$$

Since $S_{j}-q_{j} \geq 1 / 3$, it holds that $\max \left\{\bar{S}_{i}^{\mathrm{lh}}, \bar{S}_{i}^{\mathrm{ll}}\right\} \leq 5 / 6-q_{j} / 2$. The intervals $\left[\underline{S}_{i}^{\mathrm{lh}}, \bar{S}_{i}^{\mathrm{lh}}\right]$ and $\left[\max \left\{\underline{S}_{i}^{\mathrm{lla}}, \underline{S}_{i}^{\mathrm{llb}}\right\}, \bar{S}_{i}^{\mathrm{ll}}\right]$ are overlapping. In particular, since $q_{j} \leq 1 / 2, T_{j}=S_{j}-q_{j} \leq 1 / 2$, and $\delta \leq 1$, it holds that $\max \left\{\underline{S}_{i}^{\mathrm{lla}}, \underline{S}_{i}^{\mathrm{llb}}\right\} \leq \underline{S}_{i}^{\mathrm{lh}} \leq \bar{S}_{i}^{\mathrm{ll}}$.

The reduced profit function of firm $i$ has two local maxima if $\underline{S}_{i}^{\mathrm{lh}} \leq S_{i} \leq \min \left\{\bar{S}_{i}^{\mathrm{ll}}, \bar{S}_{i}^{\mathrm{lh}}\right\}$. Since $\bar{S}_{i}^{\mathrm{lh}} \leq \bar{S}_{i}^{\mathrm{ll}}$ if and only if $q_{j} \geq S_{j}-\frac{8+7 \delta}{24+18 \delta}$, the profit function has two local maxima if

$$
S_{j}-\frac{1}{2} \leq q_{j} \leq S_{j}-\frac{8+7 \delta}{24+18 \delta} \text { and } \underline{S}_{i}^{\mathrm{lh}} \leq S_{i} \leq \bar{S}_{i}^{\mathrm{ll}}
$$

or

$$
S_{j}-\frac{8+7 \delta}{24+18 \delta} \leq q_{j} \leq S_{j}-\frac{1}{3} \text { and } \underline{S}_{i}^{\mathrm{lh}} \leq S_{i} \leq \bar{S}_{i}^{\mathrm{lh}}
$$

To find the global maximum, we compare the profits in both local maxima. The profits corresponding to $q_{i}^{\text {lh }}$ and $q_{i}^{\text {ll }}$ are respectively

$$
\begin{aligned}
& \Pi_{i}^{\mathrm{lh}}=\frac{4+4 q_{j}^{2}-4 \delta+16 \delta S_{i}+8 \delta S_{i}^{2}+\delta^{2}+-8 q_{j}+4 \delta q_{j}-8 S_{i} \delta q_{j}}{16+8 \delta}, \\
& \Pi_{i}^{\mathrm{Il}}=\frac{1-2 \delta+\delta^{2}-2 q_{j}+2 \delta^{2} q_{j}+q_{j}^{2}+2 \delta q_{j}^{2}+\delta^{2} q_{j}^{2}+8 \delta S_{i}-4 \delta S_{i}^{2}+2 \delta S_{j}-2 \delta^{2} S_{j}-2 \delta q_{j} S_{j}-2 \delta^{2} q_{j} S_{j}-4 \delta S_{i} S_{j}+\delta^{2} S_{j}^{2}}{4+4 \delta} .
\end{aligned}
$$

It holds that $\Pi_{i}^{\mathrm{lh}} \geq \Pi_{i}^{\mathrm{ll}}$ if and only if $S_{i} \geq \tilde{S}_{i}$, where

$$
\tilde{S}_{i}=1-\frac{1}{2} q_{j}-\left(1+\frac{1}{2} \delta\right) T_{j}+\left(\frac{1}{2}-T_{j}\right) \sqrt{(1+\delta)\left(1+\frac{1}{2} \delta\right)}
$$

Since $\tilde{S}_{i}>\underline{S}_{i}^{\mathrm{lh}}$ whenever $q_{j} \geq S_{j}-\frac{1}{2}$, $q_{i}^{\mathrm{lh}}$ maximizes profits for $\tilde{S}_{i} \leq S_{i} \leq \bar{S}_{i}^{\mathrm{lh}}$.

Since $\max \left\{\underline{S}_{i}^{\text {lla }}, \underline{S}_{i}^{\text {llb }}\right\} \leq \tilde{S}_{i} \leq \bar{S}_{i}^{\text {ll }}, q_{i}^{\text {ll }}$ maximizes profits for $\max \left\{\underline{S}_{i}^{\text {lla }}, \underline{S}_{i}^{\text {llb }}\right\} \leq S_{i} \leq \tilde{S}_{i}$.

When $\max \left\{\bar{S}_{i}^{\mathrm{ll}}\left(q_{j}\right), \bar{S}_{i}^{\mathrm{lh}}\left(q_{j}\right)\right\}<S_{i} \leq \frac{5}{6}-\frac{1}{2} q_{j}$ we have a boundary solution, and profit maximizing sales are given by $q_{i}^{*}=S_{i}-\frac{1}{3}$.

One possibility remains: $\max \left\{\bar{S}_{i}^{\mathrm{lh}}, \tilde{S}_{i}\right\}<S_{i} \leq \bar{S}_{i}^{\mathrm{ll}}$. In this case, the profit maximizing choice is either $q_{i}^{\mathrm{ll}}$ or $q_{i}^{*}$. We argue that $q_{i}^{\text {ll }}$ maximizes profits, so for $\bar{S}_{i}^{\mathrm{lh}} \leq S_{i} \leq \bar{S}_{i}^{\mathrm{ll}}$, the best response of firm $i$ is $q_{i}^{\text {ll }}$.

It holds that

$$
\Pi_{i}^{\mathrm{Il}} \geq \Pi_{i}^{*}=\left(S_{i}-\frac{1}{3}\right)\left(\frac{4}{3}-S_{i}-q_{j}\right)+\frac{1}{9} \delta
$$

if and only if

$$
S_{i} \in\left[\frac{5}{6}-\frac{1}{6} \delta-\frac{1}{2} q_{j}+\frac{1}{2} \delta T_{j} \pm \frac{1}{3} \sqrt{\delta(1+\delta)\left(3 T_{j}-1\right)}\right] .
$$

Since

$$
\left[\bar{S}_{i}^{\mathrm{lh}}, \bar{S}_{i}^{\mathrm{ll}}\right] \subset\left[\frac{5}{6}-\frac{1}{6} \delta-\frac{1}{2} q_{j}+\frac{1}{2} \delta T_{j} \pm \frac{1}{3} \sqrt{\delta(1+\delta)\left(3 T_{j}-1\right)}\right]
$$

for

$$
q_{j}<S_{j}-\frac{4+5 \delta-4 \sqrt{(1+\delta)\left(1+\frac{1}{2} \delta\right)}}{6 \delta},
$$

we have our desired conclusion. 
Summarizing, the reduced best response $q_{i}^{*}$ of player $i$ against $q_{j}$ for $S_{j}-\frac{1}{2} \leq q_{j}<S_{j}-\frac{1}{3}$ is given by

$$
q_{i}^{*}= \begin{cases}0, & \text { if } 0 \leq S_{i}<\underline{S}_{i}^{\mathrm{lla}}, \\ \frac{S_{i},}{\left(1-q_{j}+2 \delta S_{i}-\delta+\delta T_{j}\right)} & \text { if } 0 \leq S_{i}<\underline{S}_{i}^{\mathrm{llb}}, \\ \frac{1-q_{j}-\frac{1}{2} \delta+\delta S_{i}}{2+\delta}, & \text { if } \max \left\{\underline{S}_{i}^{\mathrm{lla}}, \underline{S}_{i}^{\mathrm{llb}}\right\} \leq S_{i} \leq \tilde{S}_{i}, \\ \frac{\left(1-q_{j}+2 \delta S_{i}-\delta+\delta T_{j}\right)}{2+2 \delta}, & \text { if } \max \left\{\tilde{S}_{i} \leq \bar{S}_{i} \leq \bar{S}_{i}^{\mathrm{lh}}\right\}<S_{i} \leq \bar{S}_{i}^{\mathrm{ll}}, \\ S_{i}-\frac{1}{3} & \text { if } \max \left\{\bar{S}_{i}^{\mathrm{lh}}, \bar{S}_{i}^{\mathrm{ll}}\right\}<S_{i} \leq \frac{5}{6}-\frac{1}{2} q_{j}, \\ \frac{1}{2}-\frac{1}{2} q_{j}, & \text { if } \frac{5}{6}-\frac{1}{2} q_{j}<S_{i},\end{cases}
$$

where

$$
\begin{aligned}
& \tilde{S}_{i}=1-\frac{1}{2} q_{j}-\left(1+\frac{1}{2} \delta\right) T_{j}+\left(\frac{1}{2}-T_{j}\right) \sqrt{(1+\delta)\left(1+\frac{1}{2} \delta\right)}, \\
& \underline{S}_{i}^{\mathrm{lh}}=\frac{3}{2}+\frac{1}{4} \delta-\frac{1}{2} q_{j}-(2+\delta) T_{j}, \\
& \bar{S}_{i}^{\mathrm{lh}}=\frac{5}{6}-\frac{1}{12} \delta-\frac{1}{2} q_{j}, \\
& \underline{S}_{i}^{\mathrm{lla}}=\frac{1}{2 \delta}\left(q_{j}-1+\delta-\delta T_{j}\right), \\
& \underline{S}_{i}^{\mathrm{llb}}=\frac{1}{2}\left(1-\delta-q_{j}+\delta T_{j}\right), \\
& \bar{S}_{i}^{\mathrm{ll}}=\frac{3}{2}+\frac{1}{2} \delta-\frac{1}{2} q_{j}-\left(2+\frac{3}{2} \delta\right) T_{j} . \\
& \text { (C) } \quad S_{j}-\frac{1}{3} \leq q_{j} \leq S_{j}
\end{aligned}
$$

It follows from the reduced profit function (2) that, for $0 \leq q_{i}<S_{i}-\frac{1}{2}+\frac{1}{2} T_{j}$, profit is given by ( $\mathrm{Y}_{\mathrm{hl}}$ ), and for $S_{i}-\frac{1}{2}+\frac{1}{2} T_{j} \leq q_{i} \leq S_{i}$, profit is given by $\left(\mathrm{Y}_{\mathrm{ll}}\right)$. Taking the unrestricted first-order condition of the profit function in $\left(\mathrm{Y}_{\mathrm{hl}}\right)$ and $\left(\mathrm{Y}_{\mathrm{ll}}\right)$ and solving for $q_{i}$ results in $q_{i}^{\mathrm{hl}}$ and $q_{i}^{\mathrm{ll}}$ given by

$$
\begin{aligned}
q_{i}^{\mathrm{hl}} & =\frac{1}{2}-\frac{1}{2} q_{j}, \\
q_{i}^{\mathrm{ll}} & =\frac{1-q_{j}+2 \delta S_{i}-\delta+\delta T_{j}}{2+2 \delta} .
\end{aligned}
$$

It holds that $q_{i}^{\mathrm{hl}} \in\left[0, S_{i}-\frac{1}{2}+\frac{1}{2} T_{j}\right)$ if and only if $1-\frac{1}{2} S_{j}<S_{i}$. Similarly, it holds that $q_{i}^{\mathrm{ll} \in} \in\left[S_{i}-\frac{1}{2}+\frac{1}{2} T_{j}, S_{i}\right]$ if and only if $\max \left\{\frac{1}{2}\left(1-\delta-q_{j}+\delta T_{j}\right), \frac{1}{2 \delta}\left(-1+\delta+q_{j}-\delta T_{j}\right)\right\} \leq S_{i} \leq 1-\frac{1}{2} S_{j}$. We therefore find that the reduced best response $q_{i}^{*}$ of player 1 to $q_{j}$ is given by

$$
q_{i}^{*}= \begin{cases}S_{i}, & \text { if } 0 \leq S_{i}<\frac{1}{2}\left(1-\delta-q_{j}+\delta T_{j}\right), \\ 0, & \text { if } 0 \leq S_{i}<\frac{1}{2 \delta}\left(-1+\delta+q_{j}-\delta T_{j}\right), \\ \frac{1-q_{j}+2 \delta S_{i}-\delta+\delta T_{j}}{2+2 \delta}, & \text { if } \max \left\{\frac{1}{2}\left(1-\delta-q_{j}+\delta T_{j}\right), \frac{1}{2 \delta}\left(-1+\delta+q_{j}-\delta T_{j}\right)\right\} \\ & \leq S_{i} \leq 1-\frac{1}{2} S_{j}, \\ \frac{1}{2}-\frac{1}{2} q_{j}, & \text { if } 1-\frac{1}{2} S_{j}<S_{i} .\end{cases}
$$


Table 4

Reduced best response correspondence $\sigma_{i}^{\mathrm{R} *}\left(q_{j}\right)$ for $0 \leq q_{j} \leq \frac{1}{2}$.

\begin{tabular}{|c|c|c|c|}
\hline$A_{j}$ & $\left(q_{j}<S_{j}-\frac{1}{2}\right)$ & $q_{i}^{*}$ & $r_{i}^{*}$ \\
\hline 1) & $0 \leq q_{j}<\alpha_{1}$ & $S_{i}$ & \\
\hline 2) & $\alpha_{1} \leq q_{j} \leq \alpha_{2}$ & $\frac{1-q_{j}-\frac{1}{2} \delta+\delta S_{i}}{2+\delta}$ & $\frac{2 S_{i}-1+q_{j}+\frac{1}{2} \delta}{2+\delta}$ \\
\hline 3) & $\alpha_{2}<q_{j} \leq \alpha_{3}$ & $S_{i}-\frac{1}{3}$ & $\frac{1}{3}$ \\
\hline 4) & $q_{j}>\alpha_{3}$ & $\frac{1}{2}-\frac{1}{2} q_{j}$ & $\frac{1}{3}$ \\
\hline$B_{j}$ & $\left(S_{j}-\frac{1}{2} \leq q_{j}<S_{j}-\frac{1}{3}\right)$ & $q_{i}^{*}$ & $r_{i}^{*}$ \\
\hline 1) & $0 \leq q_{j}<\alpha_{4}$ & $S_{i}$ & 0 \\
\hline 2) & $q_{j}>\alpha_{5}$ & 0 & $S_{i}$ \\
\hline 3) & $\max \left\{\alpha_{4}, \alpha_{6}\right\} \leq q_{j} \leq \alpha_{5}$ & $\frac{1-q_{j}+2 \delta S_{i}-\delta+\delta T_{j}}{2+2 \delta}$ & $\frac{2 S_{i}-1+q_{j}+\delta-\delta T_{j}}{2+2 \delta}$ \\
\hline 4) & $q_{j} \leq \alpha_{6}, q_{j} \leq \alpha_{2}$ & $\frac{1-q_{j}-\frac{1}{2} \delta+\delta S_{i}}{2+\delta}$ & $\frac{2 S_{i}-1+q_{j}+\frac{1}{2} \delta}{2+\delta}$ \\
\hline 5) & $\alpha_{2}<q_{j}<\alpha_{6}, q_{j} \geq \alpha_{7}$ & $\frac{1-q_{j}+2 \delta S_{i}-\delta+\delta T_{j}}{2+2 \delta}$ & $\frac{2 S_{i}-1+q_{j}+\delta-\delta T_{j}}{2+2 \delta}$ \\
\hline 6) & $\alpha_{2}<q_{j} \leq \alpha_{3}, q_{j}<\alpha_{7}$ & $S_{i}-\frac{1}{3}$ & $\frac{1}{3}$ \\
\hline 7) & $q_{j}>\alpha_{3}$ & $\frac{1}{2}-\frac{1}{2} q_{j}$ & $\frac{1}{3}$ \\
\hline$C_{j}$ & $\left(q_{j} \geq S_{j}-\frac{1}{3}\right)$ & $q_{i}^{*}$ & $r_{i}^{*}$ \\
\hline 1) & $0 \leq q_{j}<\alpha_{4}$ & $S_{i}$ & 0 \\
\hline 2) & $q_{j}>\alpha_{5}$ & 0 & $S_{i}$ \\
\hline 3) & $\alpha_{4} \leq q_{j} \leq \alpha_{5}, S_{i} \leq \alpha_{8}$ & $\frac{1-q_{j}+2 \delta S_{i}-\delta+\delta T_{j}}{2+2 \delta}$ & $\frac{2 S_{i}-1+q_{j}+\delta-\delta T_{j}}{2+2 \delta}$ \\
\hline 4) & $S_{i}>\alpha_{8}$ & $\frac{1}{2}-\frac{1}{2} q_{j}$ & $\frac{1}{2}-\frac{1}{2} S_{j}+\frac{1}{2} q_{j}$ \\
\hline & & \multicolumn{2}{|c|}{ Explanation of the symbols } \\
\hline$\alpha_{1}$ & & \multirow{4}{*}{\multicolumn{2}{|c|}{$\begin{array}{l}1-\frac{1}{2} \delta-2 S_{i} \\
\frac{5}{3}-\frac{1}{6} \delta-2 S_{i} \\
\frac{5}{3}-2 S_{i} \\
\frac{1-\delta+\delta S_{j}-2 S_{i}}{1+\delta} \\
\frac{1-\delta+\delta S_{j}+2 \delta S_{i}}{1+\delta}\end{array}$}} \\
\hline$\alpha_{2}$ & & & \\
\hline$\alpha_{3}$ & & & \\
\hline$\alpha_{5}$ & & & \\
\hline$\alpha_{6}$ & & \multicolumn{2}{|c|}{$2 S_{i}-2+2 S_{j}+\delta S_{j}-\left(1-2 S_{j}\right) \sqrt{(1+\delta)\left(1+\frac{1}{2} \delta\right)}$} \\
\hline$\alpha_{7}$ & & \multicolumn{2}{|l|}{$\frac{2 S_{i}-3-\delta+4 S_{j}+3 \delta S_{j}}{3+3 \delta}$} \\
\hline$\alpha_{8}$ & & $1-\frac{1}{2} S_{j}$ & \\
\hline
\end{tabular}

\section{Appendix C. Subgame perfect equilibria}

We define the sets $A_{j}(1), \ldots, A_{j}(4), B_{j}(1), \ldots, B_{j}(7), C_{j}(1), \ldots, C_{j}(4)$ as the sets of quantities $q_{j}$ satisfying the constraints presented in Table 4 . Notice that each of these sets is a subset of $[0,1 / 2]$. Moreover, we define $A_{j}\left(k_{1}, \ldots, k_{\ell}\right)=A_{j}\left(k_{1}\right) \cup \cdots \cup A_{j}\left(k_{\ell}\right)$ and similarly for sets $B_{j}\left(k_{1}, \ldots, k_{\ell}\right)$ and $C_{j}\left(k_{1}, \ldots, k_{\ell}\right)$. In the proofs, we make use of Table 4 . That table presents the reduced best response of firm $i$ to a first-period sales quantity of firm $j$ with the use of coefficients $\alpha_{1}, \ldots, \alpha_{8}$. In the following, we will need the reduced best response of firm $j$ to a first-period sales quantity of firm $i$, which follows from Table 4 by reversing the roles of firm $i$ and $j$. The corresponding coefficients are denoted by $\beta_{1}, \ldots$, $\beta_{8}$.

Proposition C.1. If $\left(q_{i}^{*}, q_{j}^{*}\right)$ is a Nash equilibrium of the reduced game and $q_{j}^{*} \in A_{j}(1,2,3) \cup B_{j}(1,2,3,4,5,6) \cup C_{j}(1)$, then $S_{i}-q_{i}^{*} \leq \frac{1}{3}$, so $q_{i}^{*} \in C_{i}(1,2,3,4)$.
Proof. For $q_{j}^{*} \in A_{j}(1,3) \cup B_{j}(1,6) \cup C_{j}(1)$ it follows immediately from Table 4 that $S_{i}-q_{i}^{*} \leq \frac{1}{3}$. For $q_{j}^{*} \in A_{j}(2) \cup B_{j}(4)$,

$S_{i}-q_{i}^{*}=\frac{2 S_{i}-1+q_{j}^{*}+\frac{1}{2} \delta}{2+\delta} \leq \frac{\frac{2}{3}+\frac{1}{3} \delta}{2+\delta}=\frac{1}{3}$,

where the inequality follows from $q_{j}^{*} \leq \alpha_{2}$. For $q_{j}^{*} \in B_{j}(2)$,

$S_{i}-q_{i}^{*}<\frac{3}{4}-\frac{1}{4 \delta}-\frac{1}{2} S_{j}<\frac{1}{3}$,

where the first inequality follows from $\alpha_{5}<q_{j}^{*} \leq \frac{1}{2}$ and the second one from $\delta \leq 1$ and $S_{j}>q_{j}^{*}+\frac{1}{3} \geq \frac{1}{3}$. For $q_{j}^{*} \in B_{j}(3)$,

$$
\begin{aligned}
S_{i}-q_{i}^{*} & =\frac{2 S_{i}-1+q_{j}^{*}+\delta-\delta T_{j}}{2(1+\delta)} \leq \frac{\left(1+\delta+\sqrt{\left.(1+\delta)\left(1+\frac{1}{2} \delta\right)\right)}\right)\left(1-2 T_{j}\right)}{2(1+\delta)} \\
& \leq \frac{1+\delta+\sqrt{(1+\delta)\left(1+\frac{1}{2} \delta\right)}}{6(1+\delta)} \leq \frac{1}{3},
\end{aligned}
$$

where the first inequality follows from $q_{j}^{*} \geq \alpha_{6}$ (i.e. $S_{i} \leq S_{i}^{\mathrm{c}}$ ), the second from $\frac{1}{3}<T_{j} \leq \frac{1}{2}$ and the third one from $\delta \in(0,1]$. For $q_{j}^{*} \in B_{j}(5)$,

$S_{i}-q_{i}^{*}=\frac{2 S_{i}-1+q_{j}^{*}+\delta-\delta T_{j}}{2(1+\delta)} \leq 1-2 T_{j} \leq \frac{1}{3}$,

where the first inequality follows from $q_{j}^{*} \leq \alpha_{7}$, i.e. $S_{i} \leq \bar{S}_{i}^{\mathrm{ll}}$ and the second one from $\frac{1}{3}<T_{j} \leq \frac{1}{2}$.

Proposition C.2. If $\left(q_{i}^{*}, q_{j}^{*}\right)$ is a Nash equilibrium of the reduced game and $q_{j}^{*} \in A_{j}(4) \cup B_{j}(7) \cup C_{j}(4)$, then $S_{i}-q_{i}^{*}>\frac{1}{3}$, so $q_{i}^{*} \in A_{i}(1,2,3,4) \cup B_{i}(1$, $2,3,4,5,6,7)$.

Proof. If $q_{j}^{*} \in A_{j}(4) \cup B_{j}(7)$, then since $q_{j}^{*}>\alpha_{3}$, we have $S_{i}>\frac{5}{6}-\frac{1}{2} q_{j}^{*}$, and $q_{i}^{*}=\frac{1}{2}-\frac{1}{2} q_{j}^{*}$. Therefore, $S_{i}-q_{i}^{*}>\frac{1}{3}$. If $q_{j}^{*} \in C_{j}(4)$, then $S_{j}-q_{j}^{*} \leq \frac{1}{3}$, $S_{i}>1-\frac{1}{2} S_{j}$, and $q_{i}^{*}=\frac{1}{2}-\frac{1}{2} q_{j}^{*}$. This implies $S_{i}-q_{i}^{*}>\frac{1}{3}$.

We continue by solving for all Nash equilibria $\left(q_{i}^{*}, q_{j}^{*}\right)$ of the reduced game where $q_{j}^{*} \in A_{j}(1)$. Next, we consider Nash equilibria $\left(q_{i}^{*}\right.$, $q_{j}^{*}$ ) with $q_{j}^{*} \in A_{j}(2)$. We restrict attention to the case with $q_{i}^{*} \notin A_{i}(1)$, since using the symmetry of the firms such equilibria follow already from the first case. We continue with $q_{j}^{*} \in A_{j}(3)$, and so on.

$\mathbf{q}_{\mathbf{j}}^{*} \in \mathbf{A}_{\mathbf{j}}(1)$

It holds that

$q_{j}^{*}<S_{j}-\frac{1}{2}$,

$q_{j}^{*}<1-\frac{1}{2} \delta-2 S_{i}$

$q_{i}^{*}=\sigma_{i}^{\mathrm{R}}\left(q_{j}^{*}\right)=S_{i}$.

By Proposition C.1, $q_{i}^{*} \in C_{i}(1,2,3,4)$. This gives the following possibilities:

$q_{i}^{*} \in C_{i}(1): q_{j}^{*}=S_{j}$,

$q_{i}^{*} \in C_{i}(2): q_{j}^{*}=0$, 
$q_{i}^{*} \in C_{i}(3): q_{j}^{*}=\frac{1-S_{i}+2 \delta S_{j}-\delta}{2+2 \delta}$,

$q_{i}^{*} \in C_{i}(4): q_{j}^{*}=\frac{1}{2}-\frac{1}{2} S_{i}$

If $q_{i}^{*} \in C_{i}(2)$, then $q_{i}^{*}>\beta_{5}$ implies $S_{j}<\frac{1}{2}-\frac{1}{2 \delta}+\frac{1}{2 \delta} S_{i}<\frac{1}{2}$ by (5) and Lemma 4 , so (3) leads to a contradiction.

Next, (3) and (6) imply $S_{j}>1-\frac{1}{2} S_{i}$, whereas $q_{i}^{*} \in C_{i}(3)$ implies $q_{i}^{*} \leq \beta_{8}$, so $S_{j} \leq 1-\frac{1}{2} S_{i}$, a contradiction.

When $q_{i}^{*} \in C_{i}(4)$, then $q_{i}^{*} \geq S_{i}-\frac{1}{3}$ and $S_{j}>\beta_{8}$. These inequalities together with the inequalities (3) and (4) lead to the conclusion that $\left(q_{j}^{*}, q_{i}^{*}\right)$ is a Nash equilibrium with $q_{j}^{*} \in A_{j}(1)$ if and only if $q_{j}^{*}=\frac{1}{2}-\frac{1}{2} S_{i}, q_{i}^{*}=S_{i}, S_{j}>1-\frac{1}{2} S_{i}$, and $S_{i}<\frac{1}{3}-\frac{1}{3} \delta$.

$\mathbf{q}_{\mathbf{j}}^{*} \in \mathbf{A}_{\mathbf{j}}(2)$

It holds that

$q_{j}^{*}<S_{j}-\frac{1}{2}$,

$1-\frac{1}{2} \delta-2 S_{i} \leq q_{j}^{*} \leq \frac{5}{3}-\frac{1}{6} \delta-2 S_{i}$,

$q_{i}^{*}=\sigma_{i}^{\mathrm{R}}\left(q_{j}^{*}\right)=\frac{1-q_{j}^{*}-\frac{1}{2} \delta+\delta S_{i}}{2+\delta} \leq \frac{1}{2}$

By Proposition C.1, $q_{i}^{*} \in C_{i}(2,3,4){ }^{6}$ This gives the following possibilities:

$q_{i}^{*} \in C_{i}(2): q_{i}^{*}=\frac{1-\frac{1}{2} \delta+\delta S_{i}}{2+\delta}, q_{j}^{*}=0$,

$q_{i}^{*} \in C_{i}(3): q_{i}^{*}=\frac{1+2 \delta-\delta^{2}+\delta S_{i}+2 \delta^{2} S_{i}-2 \delta S_{j}}{3+5 \delta+2 \delta^{2}}$,

$q_{j}^{*}=\frac{2-3 \delta-\delta^{2}+8 \delta S_{j}+4 \delta^{2} S_{j}+2 \delta S_{i}}{6+10 \delta+4 \delta^{2}}$,

$q_{i}^{*} \in C_{i}(4): q_{i}^{*}=\frac{1-\delta+2 \delta S_{i}}{3+2 \delta}, q_{j}^{*}=\frac{2+3 \delta-2 \delta S_{i}}{6+4 \delta}$.

Consider $q_{i}^{*} \in C_{i}(2)$. Then $q_{i}^{*}>\beta_{5}$, so $S_{j}<\frac{-2+3 \delta+\delta^{2}-2 \delta S_{i}}{8 \delta+4 \delta^{2}}<\frac{1}{2}$, and

(8) leads to a contradiction.

Consider $q_{i}^{*} \in C_{i}(3)$. It holds that

$\frac{5+2 \delta+\delta^{2}+2 \delta S_{i}}{6+2 \delta}<S_{j} \leq 1-\frac{1}{2} S_{i}$,

where the first inequality follows from (8) and (11), and the second inequality from $S_{j} \leq \beta_{8}$. By rewriting the expression in (13), it follows that $S_{i}<\frac{1}{3}-\frac{1}{3} \delta$.

However, this is contradicted by

$S_{i} \geq \frac{1+2 \delta-\delta^{2}-2 \delta S_{j}}{3+4 \delta} \geq \frac{1}{3}-\frac{1}{3} \delta$,

where the first inequality follows from (9) and (11), and the second inequality from $S_{j} \leq \beta_{8}$.

${ }^{6}$ Note that, by Proposition C. $1, q_{i}^{*} \notin C_{i}(1)$. By Proposition C.1, if $q_{i}^{*} \in C_{i}(1)$, then $q_{j}^{*} \in C$ $j(1,2,3,4)$.
Consider $q_{i}^{*} \in C_{i}(4)$. It is implied by (9) and (12) that

$\frac{1}{3}(1-\delta) \leq S_{i} \leq \frac{1}{3}\left(2-\frac{1}{3} \delta\right)$

From (8) and (12) it follows that $S_{j}>\frac{5+5 \delta-2 \delta S_{i}}{6+4 \delta}$. In conclusion, $\left(q_{j}^{*}, q_{i}^{*}\right)$ is a Nash equilibrium with $q_{j}^{*} \in A_{j}(2)$ if and only if $q_{j}^{*}=\frac{2+3 \delta-2 \delta S_{i}}{6+4 \delta}, \quad q_{i}^{*}=\frac{1-\delta+2 \delta S_{i}}{3+2 \delta}, \quad \frac{1}{3}(1-\delta) \leq S_{i} \leq \frac{1}{3}\left(2-\frac{1}{3} \delta\right)$, and $S_{j}>\frac{5+5 \delta-2 \delta S_{i}}{6+4 \delta}$.

$\mathbf{q}_{\mathbf{j}}^{*} \in \mathbf{A}_{\mathbf{j}}(3)$

It holds that

$q_{j}^{*}<S_{j}-\frac{1}{2}$,

$\frac{5}{3}-\frac{1}{6} \delta-2 S_{i}<q_{j}^{*} \leq \frac{5}{3}-2 S_{i}$

$q_{i}^{*}=\sigma_{i}^{\mathrm{R}}\left(q_{j}^{*}\right)=S_{i}-\frac{1}{3}$

By Proposition C. $1, q_{i}^{*} \in C_{i}(2,3,4)$. This gives the following possibilities:

$q_{i}^{*} \in C_{i}(2): q_{j}^{*}=0$,

$q_{i}^{*} \in C_{i}(3): q_{j}^{*}=\frac{\frac{4}{3}-\frac{2}{3} \delta+2 \delta S_{j}-S_{i}}{2+2 \delta}$,

$q_{i}^{*} \in C_{i}(4): q_{j}^{*}=\frac{2}{3}-\frac{1}{2} S_{i}$

Consider $q_{i}^{*} \in C_{i}(2)$. Since $q_{j}^{*}=0$, the second inequality in (15) implies $S_{i} \leq \frac{5}{6}$. We have that

$\frac{1}{2}<S_{j}<\frac{S_{i}-\frac{4}{3}+\frac{2}{3} \delta}{2 \delta}$,

where the first inequality follows from (14) and the second from $q_{i}^{*}>\beta_{5}$. By rewriting the expression (16), we find that $S_{i}>\frac{4}{3}+\frac{1}{3} \delta$, contradicting $S_{i} \leq 5 / 6$.

Consider $q_{i}^{*} \in C_{i}(3)$. By (14), it should hold that

$S_{j}>1 \frac{1}{6}+\frac{1}{6} \delta-\frac{1}{2} S_{i}$

which contradicts with $S_{j} \leq \beta_{8}$.

Consider $q_{i}^{*} \in C_{i}(4)$. It holds that

$\frac{2}{3}-\frac{1}{9} \delta<S_{i} \leq \frac{2}{3}$

where both inequalities follow from (15). From (14), it follows that

$S_{j}>\frac{7}{6}-\frac{1}{2} S_{i}$

The other constraints are redundant. In conclusion, $q_{j}^{*} \in A_{j}(3)$ if and only if $q_{i}^{*} \in C_{i}(4), S_{j}>\frac{7}{6}-\frac{1}{2} S_{i}$ and $\frac{2}{3}-\frac{1}{9} \delta<S_{i} \leq \frac{2}{3}$.

$\mathbf{q}_{\mathbf{j}}^{*} \in \mathbf{A}_{\mathbf{j}}(4)$ 
It holds that

$q_{j}^{*}<S_{j}-\frac{1}{2}$,

$q_{j}^{*}>\frac{5}{3}-2 S_{i}$

We have

$q_{i}^{*}=\sigma_{i}^{\mathrm{R}}\left(q_{j}^{*}\right)=\frac{1}{2}-\frac{1}{2} q_{j} \leq \frac{1}{2}$.

By Propositions C.1 and C.2, $q_{i}^{*} \in A_{i}(4) \cup B_{i}(7) .^{7}$ This gives the following possibilities:

$q_{i}^{*} \in A_{i}(4): q_{i}^{*}=q_{j}^{*}=\frac{1}{3}$,

$q_{i}^{*} \in B_{i}(7): q_{i}^{*}=q_{j}^{*}=\frac{1}{3}$,

Consider $q_{i}^{*} \in A_{i}(4) \cup B_{i}(7)$. It follows from (17) that

$S_{j}>\frac{5}{6}$

For $q_{i}^{*} \in A_{i}(4)$, it follows from $q_{i}^{*}<S_{i}-\frac{1}{2}$ that $S_{i}>\frac{5}{6}$. Next, if $q_{i}^{*} \in B_{i}(7)$, it follows from

$S_{i}-\frac{1}{2} \leq q_{i}^{*}<S_{j}-\frac{1}{3}$

that

$\frac{2}{3}<S_{i} \leq \frac{5}{6}$

The other constraints are redundant. In conclusion, $q_{j}^{*} \in A_{j}(4)$ if and only if $q_{i}^{*} \in A_{i}(4) \cup B_{i}(7)$ and $S_{j}>\frac{5}{6}, S_{i}>\frac{2}{3}$.

$\mathbf{q}_{\mathbf{j}}^{*} \in \mathbf{B}_{\mathbf{j}}(1)$

It holds that

$S_{j}-\frac{1}{2} \leq q_{j}^{*}<S_{j}-\frac{1}{3}$

$q_{j}^{*}<\frac{1-\delta+\delta S_{j}-2 S_{i}}{1+\delta}$.

We have

$q_{i}^{*}=\sigma_{i}^{\mathrm{R}}\left(q_{j}^{*}\right)=S_{i} \leq \frac{1}{2}$

By Proposition C.1, $q_{i}^{*} \in C_{i}(2,3,4)$. This gives the following possibilities:

$q_{i}^{*} \in C_{i}(2): q_{j}^{*}=0$,

$q_{i}^{*} \in C_{i}(3): q_{j}^{*}=\frac{1-S_{i}+2 \delta S_{j}-\delta}{2+2 \delta}$,

$q_{i}^{*} \in C_{i}(4): q_{j}^{*}=\frac{1}{2}-\frac{1}{2} S_{i}$.

\footnotetext{
${ }^{7}$ Note that Proposition C.1 excludes that $q_{i}^{*} \in A_{i}(1,2,3) \cup B_{i}(1,2,3,4,5,6)$ and $q_{j}^{*} \in A_{j}(4)$.
}

For $q_{i}^{*} \in C_{i}(2)$, it can be found that

$S_{j}<\frac{1}{2 \delta}\left(S_{i}-1+\delta\right)<\frac{1}{3 \delta}(-1+\delta) \leq 0$,

where the first inequality follows from $q_{i}^{*}>\beta_{5}$, the second one from (19) and the last one from $\delta \leq 1$.

For $q_{i}^{*} \in C_{i}(3)$, (18) implies $\frac{5}{6}-\frac{1}{6} \delta-\frac{1}{2} S_{i}<S_{j} \leq 1-\frac{1}{2} S_{i}$. By (19), $S_{i}<\frac{1}{3}-\frac{1}{3} \delta$. The other constraints are redundant.

Next, $q_{i}^{*} \in C_{i}(4)$ implies $S_{j}>1-\frac{1}{2} S_{i}$, whereas (18) implies $S_{j} \leq 1-\frac{1}{2} S_{i}$, a contradiction.

In conclusion, $q_{j}^{*} \in B_{j}(1)$ if and only if $q_{i}^{*} \in C_{i}(3)$ and $\frac{5}{6}-$ $\frac{1}{6} \delta-\frac{1}{2} S_{i}<S_{j} \leq 1-\frac{1}{2} S_{i}, S_{i}<\frac{1}{3}-\frac{1}{3} \delta$

$\mathbf{q}_{\mathbf{j}}^{*} \in \mathbf{B}_{\mathbf{j}}(2)$

It holds that

$S_{j}-\frac{1}{2} \leq q_{j}^{*}<S_{j}-\frac{1}{3}$

$q_{j}^{*}>\frac{1-\delta+\delta S_{j}+2 \delta S_{i}}{1+\delta}$

We have

$q_{i}^{*}=\sigma_{i}^{\mathrm{R}}\left(q_{j}^{*}\right)=0$.

By Proposition C. $1, q_{i}^{*} \in C_{i}(2,3,4)$. This gives the following possibilities:

$q_{i}^{*} \in C_{i}(2): q_{j}^{*}=0$

$q_{i}^{*} \in C_{i}(3): q_{j}^{*}=\frac{1+2 \delta S_{j}-\delta+\delta S_{i}}{2+2 \delta}$

$q_{i}^{*} \in C_{i}(4): q_{j}^{*}=\frac{1}{2}$

For $q_{i}^{*} \in C_{i}(2)$, from $q_{i}^{*}>\beta_{5}$ it follows that $S_{j}<\frac{1}{2 \delta}\left(-1+\delta-\delta S_{i}\right) \leq 0$.

Consider $q_{i}^{*} \in C_{i}(3)$. Inequality (20) implies $S_{i}<\frac{1}{3 \delta}(-1+\delta) \leq 0$.

If $q_{i}^{*} \in C_{i}(4)$, it holds again that

$S_{i}<\frac{1}{4 \delta}\left(-1+3 \delta-2 \delta S_{j}\right)<\frac{1}{3 \delta}(-1+\delta) \leq 0$,

where the first inequality follows from (21) and the second one from $S_{j}>\beta_{8}$.

In conclusion, $q_{j}^{*} \notin B_{j}(2)$.

$\mathbf{q}_{\mathbf{j}}^{*} \in \mathbf{B}_{\mathbf{j}}(3)$

It holds that

$S_{j}-\frac{1}{2} \leq q_{j}^{*}<S_{j}-\frac{1}{3}$,

$q_{j} \geq \max \left\{\frac{1-\delta+\delta S_{j}-2 S_{i}}{1+\delta}, \frac{2 S_{i}-2+2 S_{j}+\delta S_{j}-\left(1-2 S_{j}\right) \sqrt{(1+\delta)\left(1+\frac{1}{2} \delta\right)}}{1+\delta+2 \sqrt{(1+\delta)\left(1+\frac{1}{2} \delta\right)}}\right\}$

$q_{j} \leq \frac{1-\delta+\delta S_{j}+2 \delta S_{i}}{1+\delta}$. 
We have

$q_{i}^{*}=\sigma_{i}^{R}\left(q_{j}^{*}\right)=\frac{1-q_{j}+2 \delta S_{i}-\delta+\delta S_{j}-\delta q_{j}}{2+2 \delta}$.

By Proposition C.1, $q_{i}^{*} \in C_{i}(2,3,4)$. This gives the following possibilities:

$q_{i}^{*} \in C_{i}(2): q_{i}^{*}=\frac{1+2 \delta S_{i}-\delta+\delta S_{j}}{2+2 \delta}, q_{j}^{*}=0$,

$q_{i}^{*} \in C_{i}(3): q_{i}^{*}=\frac{1-\delta+3 \delta S_{i}}{3+3 \delta}, q_{j}^{*}=\frac{1-\delta+3 \delta S_{j}}{3+3 \delta}$,

$q_{i}^{*} \in C_{i}(4): q_{i}^{*}=\frac{1-3 \delta+4 \delta S_{i}+2 \delta S_{j}}{3+3 \delta}$

$q_{j}^{*}=\frac{1+3 \delta-2 \delta S_{i}-\delta S_{j}}{3+3 \delta}$.

For $q_{i}^{*} \in C_{i}(2)$, it follows from $q_{i}^{*}>\beta_{5}$ that $S_{j}<\frac{1}{3 \delta}(-1+\delta) \leq 0$.

If $q_{i}^{*} \in C_{i}(3)$, it is implied by (23) that $\frac{1}{3}(1-\delta) \leq S_{i} \leq \frac{7}{6}-$ $S_{j}-\frac{1}{6} \delta+\frac{\sqrt{(1+\delta)\left(1+\frac{1}{2} \delta\right)}}{1+\delta}\left(\frac{5}{6}+\frac{1}{6} \delta-S_{j}\right)$. It follows from (22) that $S_{j}>\frac{2}{3}$. The remaining constraints are redundant.

Consider $q_{i}^{*} \in C_{i}(4)$. By $S_{j}>\beta_{8}$ and (23) it follows that

$2-2 S_{j}<S_{i} \leq \frac{7+10 \delta+3 \delta^{2}-6 S_{j}-10 \delta S_{j}-4 \delta^{2} S_{j}+\left(5+9 \delta-6 S_{j}-8 \delta S_{j}\right) \sqrt{(1+\delta)\left(1+\frac{1}{2} \delta\right)}}{6+8 \delta+2 \delta^{2}+4 \delta \sqrt{(1+\delta)\left(1+\frac{1}{2} \delta\right)}}$.

Such an $S_{i}$ only exists if $S_{j}>\frac{5+\delta}{6}$. From (22) it follows that $S_{i} \leq \frac{5+9 \delta-6 S_{j}-8 \delta S_{j}}{4 \delta}$. Now, there only exists an $S_{i}$ such that $2-2 S_{j}<S_{i} \leq \frac{5+9 \delta-6 S_{j}-8 \delta S_{j}}{4 \delta}$, if $S_{j}<\frac{5+\delta}{6}$, a contradiction.

In conclusion, $q_{j}^{*} \in B_{j}(3)$ if and only if $q_{i}^{*} \in C_{i}(3)$ and $\frac{1}{3}(1-\delta) \leq S_{i} \leq \frac{7}{6}-$ $S_{j}-\frac{1}{6} \delta+\frac{\sqrt{(1+\delta)\left(1+\frac{1}{2} \delta\right)}}{1+\delta}\left(\frac{5}{6}+\frac{1}{6} \delta-S_{j}\right), S_{j}>\frac{2}{3}$.

$\mathbf{q}_{\mathbf{j}}^{*} \in \mathbf{B}_{\mathbf{j}}(4)$

It holds that

$S_{j}-\frac{1}{2} \leq q_{j}^{*}<S_{j}-\frac{1}{3}$

$q_{j}<\frac{2 S_{i}-2+2 S_{j}+\delta S_{j}-\left(1-2 S_{j}\right) \sqrt{(1+\delta)\left(1+\frac{1}{2} \delta\right)}}{1+\delta+2 \sqrt{(1+\delta)\left(1+\frac{1}{2} \delta\right)}}$

$q_{j} \leq \frac{5}{3}-\frac{1}{6} \delta-2 S_{i}$

We have

$q_{i}^{*}=\sigma_{i}^{R}\left(q_{j}^{*}\right)=\frac{1-q_{j}-\frac{1}{2} \delta+\delta S_{i}}{2+\delta}$.
By Proposition C. $1, q_{i}^{*} \in C_{i}(2,3,4)$. This gives the following possibilities:

$q_{i}^{*} \in C_{i}(2): q_{i}^{*}=\frac{1-\frac{1}{2} \delta+\delta S_{i}}{2+\delta}, q_{j}^{*}=0$,

$q_{i}^{*} \in C_{i}(3): q_{i}^{*}=\frac{1+2 \delta-\delta^{2}+\delta S_{i}+2 \delta^{2} S_{i}-2 \delta S_{j}}{3+5 \delta+2 \delta^{2}}$,

$q_{j}^{*}=\frac{2-3 \delta-\delta^{2}+8 \delta S_{j}+4 \delta^{2} S_{j}+2 \delta S_{i}}{6+10 \delta+4 \delta^{2}}$

$q_{i}^{*} \in C_{i}(4): q_{i}^{*}=\frac{1-\delta+2 \delta S_{i}}{3+2 \delta}, q_{j}^{*}=\frac{2+3 \delta-2 \delta S_{i}}{6+4 \delta}$.

For $q_{i}^{*} \in C_{i}(2), q_{i}>\beta_{5}$ and inequality (25) imply respectively that $\frac{1}{3}<S_{j}<\frac{-1+\frac{3}{2} \delta+\frac{1}{2} \delta^{2}-\delta S_{i}}{2 \delta(2+\delta)}$. However, no such $S_{j}$ exists, since this would imply that $S_{i}<\frac{1}{\delta}\left(-1+\frac{1}{6} \delta-\frac{1}{6} \delta^{2}\right) \leq 0$.

Consider $q_{i}^{*} \in C_{i}(3)$. It follows from (26) and $q_{i}<\beta_{5}$ that

$\frac{7+9 \frac{1}{2} \delta+2 \delta^{2}-\frac{1}{2} \delta^{3}-6 S_{j}-9 \delta S_{j}-3 \delta^{2} S_{j}+\left(5+2 \delta+\delta^{2}-6 S_{j}-2 \delta S_{j}\right) \sqrt{(1+\delta)\left(1+\frac{1}{2} \delta\right)}}{6+9 \delta+3 \delta^{2}-2 \delta \sqrt{(1+\delta)\left(1+\frac{1}{2} \delta\right)}}$

$<S_{i} \leq 2-2 S_{j}$

and from (25) and $q_{i}<\beta_{5}$ that

$\frac{6 S_{j}+2 \delta S_{j}-5-2 \delta-\delta^{2}}{2 \delta} \leq S_{i} \leq 2-2 S_{j}$.

There exists an $S_{i}$ such that (28) if and only if $S_{j}>\frac{5+\delta}{6}$ and there exists an $S_{i}$ such that (29) holds if and only if $S_{j} \leq \frac{5+\delta}{6}$, a contradiction.

If $q_{i}^{*} \in C_{i}(4)$, inequality (27) implies $S_{i} \leq \frac{1}{3}\left(2-\frac{1}{3} \delta\right)$. It follows from (26) and (25) respectively that $S_{j}>$ $\frac{7+6 \frac{1}{2} \delta+\frac{3}{2} \delta^{2}-6 S_{i}-5 \delta S_{i}-\delta^{2} S_{i}+\left(5+5 \delta-2 \delta S_{i}\right) \sqrt{(1+\delta)\left(1+\frac{1}{2} \delta\right)}}{6+7 \delta+2 \delta^{2}+(6+4 \delta) \sqrt{(1+\delta)\left(1+\frac{1}{2} \delta\right)}}$ and $S_{j} \leq \frac{5+5 \delta-2 \delta S_{i}}{6+4 \delta}$. The other constraints are redundant.

In conclusion, $q_{j}^{*} \in B_{j}(4)$ if and only if $q_{i}^{*} \in C_{i}(4)$ and $S_{i} \leq$ $\frac{1}{3}\left(2-\frac{1}{3} \delta\right), \frac{7+6 \frac{1}{2} \delta+\frac{3}{2} \delta^{2}-6 S_{i}-5 \delta S_{i}-\delta^{2} S_{i}+\left(5+5 \delta-2 \delta S_{i}\right) \sqrt{(1+\delta)\left(1+\frac{1}{2} \delta\right)}}{6+7 \delta+2 \delta^{2}+(6+4 \delta) \sqrt{(1+\delta)\left(1+\frac{1}{2} \delta\right)}}<$ $\left.S_{j} \leq \frac{5+5 \delta-2 \delta S_{i}}{6+4 \delta}\right)$

$\mathbf{q}_{\mathbf{j}}^{*} \in \mathbf{B}_{\mathbf{j}}(5)$

It holds that

$S_{j}-\frac{1}{2} \leq q_{j}^{*}<S_{j}-\frac{1}{3}$, 
$\frac{5}{3}-\frac{1}{6} \delta-2 S_{i}<q_{j}<\frac{2 S_{i}-2+2 S_{j}+\delta S_{j}-\left(1-2 S_{j}\right) \sqrt{(1+\delta)\left(1+\frac{1}{2} \delta\right)}}{1+\delta+2 \sqrt{(1+\delta)\left(1+\frac{1}{2} \delta\right)}}$

$q_{j} \geq \frac{2 S_{i}-3-\delta+4 S_{j}+3 \delta S_{j}}{3+3 \delta}$.

We have

$q_{i}^{*}=\sigma_{i}^{R}\left(q_{j}^{*}\right)=\frac{1-q_{j}+2 \delta S_{i}-\delta+\delta S_{j}-\delta q_{j}}{2+2 \delta}$.

By Proposition C.1, $q_{i}^{*} \in C_{i}(2,3,4)$. This gives the following possibilities:

$q_{i}^{*} \in C_{i}(2): q_{i}^{*}=\frac{1+2 \delta S_{i}-\delta+\delta S_{j}}{2+2 \delta}, q_{j}^{*}=0$,

$q_{i}^{*} \in C_{i}(3): q_{i}^{*}=\frac{1-\delta+3 \delta S_{i}}{3+3 \delta}, q_{j}^{*}=\frac{1-\delta+3 \delta S_{j}}{3+3 \delta}$,

$q_{i}^{*} \in C_{i}(4): q_{i}^{*}=\frac{1-3 \delta+4 \delta S_{i}+2 \delta S_{j}}{3+3 \delta}$,

$q_{j}^{*}=\frac{1+3 \delta-2 \delta S_{i}-\delta S_{j}}{3+3 \delta}$.

For $q_{i}^{*} \in C_{i}(2)$, it follows from $q_{i}>\beta_{6}$ that $S_{j}<\frac{1}{3 \delta}(-1+\delta) \leq 0$.

For $q_{i}^{*} \in C_{i}(3)$, it holds that $S_{j} \leq 1-\frac{1}{2} S_{i}$. It is implied by (31) that $S_{i}>\max \left\{\frac{4+5 \frac{1}{2} \delta-\frac{1}{2} \delta^{2}-3 \delta S_{j}}{6+6 \delta}, \frac{7}{6}-\frac{1}{6} \delta-S_{j}+\frac{\sqrt{(1+\delta)\left(1+\frac{1}{2} \delta\right)}}{1+\delta}\left(\frac{5}{6}+\frac{1}{6} \delta-S_{j}\right)\right\}$. From (30) it follows that $S_{j}>\frac{2}{3}$. The other constraints are redundant.

If $q_{i}^{*} \in C_{i}(4)$, it holds that $S_{j}>1-\frac{1}{2} S_{i}$. From (32) it follows that $S_{j} \leq 1-\frac{1}{2} S_{i}$, a contradiction.

In conclusion, $q_{j}^{*} \in B_{j}(5)$ if and only if $q_{i}^{*} \in C_{i}(3)$ and $S_{i}>\max \left\{\frac{4+5 \frac{1}{2} \delta-\frac{1}{2} \delta^{2}-3 \delta S_{j}}{6+6 \delta}, \frac{7}{6}-\frac{1}{6} \delta-S_{j}+\frac{\sqrt{(1+\delta)\left(1+\frac{1}{2} \delta\right)}}{1+\delta}\left(\frac{5}{6}+\frac{1}{6} \delta-S_{j}\right)\right\}$, $\frac{2}{3}<S_{j} \leq 1-\frac{1}{2} S_{i}$

$\mathbf{q}_{\mathbf{j}}^{*} \in \mathbf{B}_{\mathbf{j}}(6)$

It holds that

$S_{j}-\frac{1}{2} \leq q_{j}^{*}<S_{j}-\frac{1}{3}$,

$\frac{5}{3}-\frac{1}{6} \delta-2 S_{i}<q_{j} \leq \frac{5}{3}-2 S_{i}$,

$q_{j}<\frac{2 S_{i}-3-\delta+4 S_{j}+3 \delta S_{j}}{3+3 \delta}$

We have

$q_{i}^{*}=\sigma_{i}^{\mathrm{R}}\left(q_{j}^{*}\right)=S_{i}-\frac{1}{3}$.
By Proposition C.1, $q_{i}^{*} \in C_{i}(2,3,4)$. This gives the following possibilities:

$q_{i}^{*} \in C_{i}(2): q_{j}^{*}=0$,

$q_{i}^{*} \in C_{i}(3): q_{j}^{*}=\frac{\frac{4}{3}-\frac{2}{3} \delta+2 \delta S_{j}-S_{i}}{2+2 \delta}$

$q_{i}^{*} \in C_{i}(4): q_{j}^{*}=\frac{2}{3}-\frac{1}{2} S_{i}$.

For $q_{i}^{*} \in C_{i}(2)$. It holds that

$S_{j} \leq \frac{1}{2 \delta}\left(S_{i}-\frac{4}{3}+\frac{2}{3} \delta\right) \leq \frac{1}{2 \delta}\left(-\frac{1}{2}+\frac{2}{3} \delta\right) \leq \frac{1}{3}$,

where the first inequality follows from (36) and the second one from (34). This contradicts with (33).

Consider $q_{i}^{*} \in C_{i}(3)$. It holds that $S_{j} \leq 1-\frac{1}{2} S_{i}$. From (33) it follows that $S_{j}>1-\frac{1}{2} S_{i}$, a contradiction.

Next, if $q_{i}^{*} \in C_{i}(4)$, it follows from (33) that $S_{j} \leq \frac{7}{6}-\frac{1}{2} S_{i}$. By (34) and by (35) it is implied respectively that $\frac{1}{3}\left(2-\frac{1}{3} \delta\right)<S_{i} \leq \frac{2}{3}$ and $S_{j}>\frac{10+6 \delta-7 S_{i}-3 \delta S_{i}}{8+6 \delta}$. The other constraints are redundant.

In conclusion, $q_{j}^{*} \in B_{j}(6)$ if and only if $q_{i}^{*} \in C_{i}(4)$ and $\frac{1}{3}\left(2-\frac{1}{3} \delta\right)<S_{i} \leq \frac{2}{3}, \frac{10+6 \delta-7 S_{i}-3 \delta S_{i}}{8+6 \delta}<S_{j} \leq \frac{7}{6}-\frac{1}{2} S_{i}$.

$\mathbf{q}_{\mathbf{j}}^{*} \in \mathbf{B}_{\mathbf{j}}(7)$

It holds that

$S_{j}-\frac{1}{2} \leq q_{j}^{*}<S_{j}-\frac{1}{3}$,

$q_{j}^{*}>\frac{5}{3}-2 S_{i}$.

We have

$q_{i}^{*}=\sigma_{i}^{\mathrm{R}}\left(q_{j}^{*}\right)=\frac{1}{2}-\frac{1}{2} q_{j} \leq \frac{1}{2}$.

By Propositions C.1 and C.2, $q_{i}^{*} \in B_{i}(7)$. This gives the following possibilities:

$q_{i}^{*} \in B_{i}(7): q_{i}^{*}=q_{j}^{*}=\frac{1}{3}$.

For $q_{i}^{*} \in B_{j}(7)$, it follows from $S_{i}-\frac{1}{2} \leq q_{i}^{*}<S_{j}-\frac{1}{2}$ that $\frac{2}{3}<S_{i} \leq \frac{5}{6}$. From (37) it follows that $\frac{2}{3}<S_{j} \leq \frac{5}{6}$. The rest of the constraints is redundant.

Therefore, $q_{j}^{*} \in B_{j}(7)$ if $q_{i}^{*} \in B_{i}(7)$ and $\frac{2}{3}<S_{i} \leq \frac{5}{6}, \frac{2}{3}<S_{j} \leq \frac{5}{6}$.

$\mathbf{q}_{\mathbf{j}}^{*} \in \mathbf{C}_{\mathbf{j}}(1)$

It holds that

$q_{j}^{*} \geq S_{j}-\frac{1}{3}$,

$q_{j}^{*}<\frac{1-\delta+\delta S_{j}-2 S_{i}}{1+\delta}$. 
We have

$q_{i}^{*}=\sigma_{i}^{\mathrm{R}}\left(q_{j}^{*}\right)=S_{i} \leq \frac{1}{2}$.

By Propositions C.1 and C.2, $q_{i}^{*} \in C_{i}(1,2,3)$. This gives the following possibilities:

$q_{i}^{*} \in C_{i}(1): q_{j}^{*}=S_{j}$,

$q_{i}^{*} \in C_{i}(2): q_{j}^{*}=0$

$q_{i}^{*} \in C_{i}(3): q_{j}^{*}=\frac{1-S_{i}+2 \delta S_{j}-\delta}{2+2 \delta}$.

If $q_{i}^{*} \in C_{i}(1)$, then, by $q_{i}<\beta_{4}$, it holds that $S_{j}<\frac{1}{2}-\frac{1}{2} \delta-\frac{1}{2} S_{i}$. From (39), it follows that $S_{i}<\frac{1}{2}-\frac{1}{2} \delta-\frac{1}{2} S_{j}$.

Consider $q_{i}^{*} \in C_{i}(2)$. It holds that

$S_{j}<\frac{1}{2 \delta}\left(S_{i}-1+\delta\right)<\frac{1}{3 \delta}(-1+\delta) \leq 0$,

where the first inequality follows from $q_{i}>\beta_{5}$ and the second one from (39).

For $q_{i}^{*} \in C_{i}(3)$, it follows from $q_{i}^{*} \geq \beta_{4}$ that $S_{j} \geq \frac{1}{2}-\frac{1}{2} \delta-\frac{1}{2} S_{i}$. By (39), it is implied that $S_{i}<\frac{1}{3}-\frac{1}{3} \delta$. From (38), it follows that $S_{j} \leq \frac{5}{6}-\frac{1}{6} \delta-\frac{1}{2} S_{i}$. The rest of the constraints is redundant.

In conclusion, $q_{j}^{*} \in C_{j}(1)$ if and only if $q_{i}^{*} \in C_{i}(1)$ and $S_{i}<\frac{1}{2}-$ $\frac{1}{2} \delta-\frac{1}{2} S_{j}, S_{j}<\frac{1}{2}-\frac{1}{2} \delta-\frac{1}{2} S_{i} \quad$ or $\quad q_{i}^{*} \in C_{i}(3) \quad$ and $\quad S_{i}<\frac{1}{3}-\frac{1}{3} \delta, \frac{1}{2}-$ $\frac{1}{2} \delta-\frac{1}{2} S_{i} \leq S_{j} \leq \frac{5}{6}-\frac{1}{6} \delta-\frac{1}{2} S_{i}$.

$\mathbf{q}_{\mathbf{j}}^{*} \in \mathbf{C}_{\mathbf{j}}(2)$

It holds that

$q_{j}^{*} \geq S_{j}-\frac{1}{3}$,

$q_{j}^{*}>\frac{1-\delta+\delta S_{j}+2 \delta S_{i}}{1+\delta}$.

We have

$q_{i}^{*}=\sigma_{i}^{\mathrm{R}}\left(q_{j}^{*}\right)=0$

By Proposition C. $2, q_{i}^{*} \in C_{i}(2,3)$. This gives the following possibilities:

$q_{i}^{*} \in C_{i}(2): q_{j}^{*}=0$,

$q_{i}^{*} \in C_{i}(3): q_{j}^{*}=\frac{1+2 \delta S_{j}-\delta+\delta S_{i}}{2+2 \delta}$.

For $q_{i}^{*} \in C_{i}(2)$, it follows from (40) that $S_{i}<\frac{1}{2 \delta}\left(-1+\delta-\delta S_{j}\right) \leq 0$.

For $q_{i}^{*} \in C_{i}(3)$, it is implied by $(40)$ that $S_{i}<\frac{1}{3 \delta}(-1+\delta) \leq 0$.

In conclusion, $q_{j}^{*} \notin C_{j}(2)$ if $q_{i}^{*} \in C_{i}(2,3)$.

$\mathbf{q}_{\mathbf{j}}^{*} \in \mathbf{C}_{\mathbf{j}}(3)$

It holds that

$q_{j}^{*} \geq S_{j}-\frac{1}{3}$, $\frac{1-\delta+\delta S_{j}-2 S_{i}}{1+\delta} \leq q_{j}^{*} \leq \frac{1-\delta+\delta S_{j}+2 \delta S_{i}}{1+\delta}$,

$S_{i} \leq 1-\frac{1}{2} S_{j}$

We have

$q_{i}^{*}=\sigma_{i}^{\mathrm{R}}\left(q_{j}^{*}\right)=\frac{1-q_{j}+2 \delta S_{i}-\delta+\delta S_{j}-\delta q_{j}}{1+\delta}$.

By Proposition C.2, $q_{i}^{*} \in C_{i}(3)$. This gives the following possibility:

$q_{i}^{*} \in C_{i}(3): q_{i}^{*}=\frac{1-\delta+3 \delta S_{i}}{3+3 \delta}, q_{j}^{*}=\frac{1-\delta+3 \delta S_{j}}{3+3 \delta}$.

For $q_{i}^{*} \in C_{i}(3)$, it follows from $q_{i}^{*} \geq S_{i}-\frac{1}{3}$ and (41) respectively that $S_{i} \leq \frac{2}{3}$ and $S_{j} \leq \frac{2}{3}$.

Since $q_{i}^{*} \in C_{i}(3)$ and by (41), $S_{i} \leq \frac{2}{3}$ and $S_{j} \leq \frac{2}{3}$. Next, it follows from $q_{i}^{*} \geq \beta_{4}$ that $S_{j} \geq \frac{1}{3}-\frac{1}{3} \delta$. By (42), $S_{i} \geq \frac{1}{3}-\frac{1}{3} \delta$. The remaining constraints are redundant.

In sum, $q_{j}^{*} \in C_{j}(3)$ if $q_{i}^{*} \in C_{i}(3)$ and $\frac{1}{3}(1-\delta) \leq S_{i} \leq \frac{2}{3}, \frac{1}{3}(1-\delta) \leq S_{j} \leq \frac{2}{3}$.

$\mathbf{q}_{\mathbf{j}}^{*} \in \mathbf{C}_{\mathbf{j}}(4)$

This case does not need to be derived as by Proposition C.2 it can only be combined with situations $A_{i}$ and $B_{i}$, which have been calculated above.

\section{References}

Besanko, D., Doraszelski, U., 2004. Capacity dynamics and endogenous asymmetries in firm size. RAND Journal of Economics 35, 23-49.

Biglaiser, G., Vettas, N., 2004. Dynamic price competition with capacity constraints and strategic buyers. CEPR Discussion Paper No. 4315.

Bikhchandani, S., Mamer, J., 1993. A duopoly model of pricing for inventory liquidation. European Journal of Operational Research 69, 177-186.

Cournot, A.A., 1838. Researches into the Mathematical Principles of the Theory of Wealth. N.T. Bacon trans., Kelly, A.M. (1971), New York.

Gabszewicz, J., Poddar, S., 1997. Demand fluctuations and capacity utilization under duopoly. Economic Theory 10, 131-146.

Gaudet, G., Van Long, N., 1994. On the effects of the distribution of initial endowments in a nonrenewable resource duopoly. Journal of Economic Dynamics and Control 18, 1189-1198.

Glicksberg, I.L., 1952. A further generalization of the Kakutani fixed point theorem, with application to Nash equilibrium points. Proceedings of the American Mathematical Society $3,170-174$.

Hotelling, H., 1931. The economics of exhaustible resources. Journal of Political Economy 39, 1158-1167.

Kovenock, D., Roy, S., 1998. Dynamic capacity choice in a Betrand-Edgeworth framework. Journal of Mathematical Economics 29, 135-160.

Kreps, D., Scheinkman, J., 1983. Quantity precommitment and Bertrand competition yield Cournot outcomes. The Bell Journal of Economics 14, 326-337.

Krishnan, K., Röller, L.-H., 1993. Preemptive investment with resalable capacity. RAND Journal of Economics 24, 479-502.

Laye, J., Laye, M., 2008. Uniqueness and characterization of capacity constrained CournotNash equilibrium. Operations Research Letters 36, 168-172.

Levitan, R., Shubik, M., 1972. Price duopoly and capacity constraints. International Economic Review 13, 111-121.

Lewis, T., Schmalensee, R., 1980. On oligopolistic markets for nonrenewable natural resources. The Quarterly Journal of Economics 95, 475-491.

Loury, G., 1986. A theory of 'Oil'Igopoly: Cournot equilibrium in exhaustible resource markets with fixed supplies. International Economic Review 27, 285-301.

Osborne, M., Pitchik, C., 1986. Price competition in a capacity-constraint duopoly. Journal of Economic Theory 38, 238-260.

Pal, D., 1991. Cournot duopoly with two production periods and cost differentials. Journal of Economic Theory 55, 441-448.

Pal, D., 1996. Endogenous Stackelberg equilibria with identical firms. Games and Economic Behavior 12, 81-94.

Reinganum, J., Stokey, N., 1985. Oligopoly extraction of a common property natural resource: the importance of the period of commitment in dynamic games. International Economic Review 26, 161-173.

Salo, S., Tahvonen, O., 2001. Oligopoly equilibria in nonrenewable resource markets Journal of Economic Dynamics and Control 25, 671-702.

Saloner, G., 1987. Cournot duopoly with two production periods. Journal of Economic Theory 42, 183-187. 